\title{
ESR and EISCAT observations of the response of the cusp and cleft to IMF orientation changes
}

\author{
I. W. McCrea ${ }^{1}$, M. Lockwood ${ }^{1,2}$, J. Moen $^{3}$, F. Pitout ${ }^{4}$, P. Eglitis ${ }^{4}$, A. D. Aylward ${ }^{5}$, J.-C. Cerisier ${ }^{6}$, \\ A. Thorolfssen ${ }^{6}$, S. E. Milan ${ }^{7}$ \\ ${ }^{1}$ Space Science Department, Rutherford Appleton Laboratory, Chilton, Oxon., OX11 0QX, UK \\ 2 Department of Physics and Astronomy, Southampton University, UK \\ 3 Arctic Geophysics, University Courses on Svalbard, Longyearbyen, Norway \\ ${ }^{4}$ Institutet för Rymdfysik, Uppsala, Sweden \\ 5 Atmospheric Physics Laboratory, University College London, UK \\ ${ }^{6}$ Centre d'étude des Environnements Terrestre et Planétaires, F-78140 Velizy, France \\ ${ }^{7}$ Department of Physics and Astronomy, University of Leicester, UK
}

Received: 21 December 1999 / Revised: 1 June 2000 / Accepted: 7 June 2000

\begin{abstract}
We report observations of the cusp/cleft ionosphere made on December 16th 1998 by the EISCAT (European incoherent scatter) VHF radar at Tromsø and the EISCAT Svalbard radar (ESR). We compare them with observations of the dayside auroral luminosity, as seen by meridian scanning photometers at Ny Ålesund and of HF radar backscatter, as observed by the CUTLASS radar. We study the response to an interval of about one hour when the interplanetary magnetic field (IMF), monitored by the WIND and ACE spacecraft, was southward. The cusp/cleft aurora is shown to correspond to a spatially extended region of elevated electron temperatures in the VHF radar data. Initial conditions were characterised by a northward-directed IMF and cusp/cleft aurora poleward of the ESR. A strong southward turning then occurred, causing an equatorward motion of the cusp/cleft aurora. Within the equatorward expanding, southward-IMF cusp/cleft, the ESR observed structured and elevated plasma densities and ion and electron temperatures. Cleft ion fountain upflows were seen in association with elevated ion temperatures and rapid eastward convection, consistent with the magnetic curvature force on newly opened field lines for the observed negative IMF $B_{y}$. Subsequently, the ESR beam remained immediately poleward of the main cusp/cleft and a sequence of poleward-moving auroral transients passed over it. After the last of these, the ESR was in the polar cap and the radar observations were characterised by extremely low ionospheric densities and downward field-aligned flows. The IMF then turned northward again and the auroral oval contracted such that the ESR moved back into the cusp/cleft region. For the poleward-retreating, northward-IMF cusp/cleft, the convection flows were slower, upflows were weaker and the electron density and temperature enhancements were less structured. Following the northward turning, the bands of high electron temperature and cusp/cleft aurora bifurcated, consistent with
\end{abstract}

Correspondence to: I. W. McCrea both subsolar and lobe reconnection taking place simultaneously. The present paper describes the largescale behaviour of the ionosphere during this interval, as observed by a powerful combination of instruments. Two companion papers, by Lockwood et al. (2000) and Thorolfsson et al. (2000), both in this issue, describe the detailed behaviour of the poleward-moving transients observed during the interval of southward $B_{z}$, and explain their morphology in the context of previous theoretical work.

Key words: Ionosphere (ionosphere - magnetosphere interactions; auroral ionosphere; plasma temperature and density)

\section{Introduction}

In December 1998, an extended campaign of measurements took place involving observations of the EISCAT Svalbard radar, the EISCAT Tromsø VHF radar and a number of other diagnostics including meridian scanning photometers at Longyearbyen and Ny Ålesund. The major motivations of these experiments were to take advantage of the dark conditions during the noon sector, which allowed optical observations of the cusp to be made from Svalbard, and the possibility to combine these optical observations with data from the EISCAT Svalbard radar which ran a new radar experiment to probe the whole range of altitudes from 90 to $1000 \mathrm{~km}$. This was the first occasion when such observations could be combined in this way. The observing campaign, which lasted from December 11 th to 22nd, yielded a large amount of interesting data. In this paper, we concentrate on the observations obtained on December 16th, a day that was particularly favourable in terms of both cloud cover and geomagnetic conditions. 


\subsection{The cusp and the cleft}

The cusp region is where solar wind plasma has direct access to the upper atmosphere. Modelling shows how this is made possible by magnetic reconnection between the geomagnetic field and the draped interplanetary magnetic field (IMF) in the magnetosheath, generating open field lines that connect the magnetosphere with the magnetosheath and along which plasma is free to flow across the magnetopause boundary (Onsager et al., 1993; Lockwood and Smith, 1994; Lockwood, 1995; Onsager and Lockwood, 1997; Fedorov et al., 1999). Plasma crossing the dayside magnetopause along newly opened field lines is accelerated Earthward, so that the particles with low pitch angles can precipitate to low altitudes. (As first reported by Rosenbauer et al., 1975, particles with larger pitch angles mirror in the converging magnetic field lines and subsequently travel antisunward into the tail lobe to become part of the "mantle" population there.) On the other hand, particles that enter the magnetopause on field lines that have been opened for longer are decelerated on crossing the tail magnetopause and are swept directly into the tail by the anti-sunward convection.

The cleft region is more extensive in local time than the cusp, and was for many years considered to be the signature of a torus of closed boundary field lines, called low-latitude boundary layer (LLBL) (Hones et al., 1972; Akasofu et al., 1973; Eastman et al., 1976; Haerendel et al., 1978). The cleft has lower plasma densities than the cusp but higher ion energies. However, the differences between the particle spectra of cusp and cleft were not quantified until the work of Newell and Meng (1988, 1992). The mechanism responsible for populating closed field lines with magnetosheath plasma is not understood. Wave-driven diffusion is known to be inadequate (Lotko and Sonnerup, 1995; Treumann et al., 1995; Winske et al., 1995) and so it has been proposed that the plasma enters because LLBL field lines are opened but subsequently re-closed, as modelled by Richard et al. (1994). A small-scale patchy reconnection mechanism for this was proposed by Nishida (1989) whereas Song and Russell (1992) invoked large-scale lobe reconnection in both hemispheres.

More recently, it has been argued that the cleft and cusp precipitations do not reflect two different source regions and two different injection mechanisms that allow magnetosheath plasma to cross the magnetopause, but are simply stages in a single evolution. The discontinuity in that evolution is very slight and is explained by recent modelling that allows for ion time-of-flight effects and ion acceleration at the magnetopause and/or at the bow shock (respectively, Lockwood et al., 1996 and Fuselier et al., 1999). Counter-streaming electrons observed in the equatorial LLBL (Ogilvie et al., 1984; Hall et al., 1991) can be explained as coming from the magnetosheath rather than the ionosphere. The mirroring of these electrons explains the observed symmetry of the populations flowing parallel and antiparallel to the magnetic field, without the need to invoke identical ionospheric sources in the two hemispheres.
In this concept the cleft, like the cusp, is on open field lines, the differences between the precipitation spectra arising because the cleft is either on the most recently opened field lines or on field lines that were reconnected away from noon where magnetosheath densities are lower (see also Lockwood and Moen, 1996). A hybrid view has been proposed by Newell and Meng (1998) who suggest that the cleft is indeed open near noon but on closed field lines nearer dawn and dusk.

Both cusp and cleft precipitations generate predominantly $630 \mathrm{~nm}$ (red-line) emissions (with much lower intensities of $557.7 \mathrm{~nm}$ green-line emissions) when impacting the oxygen atoms of the upper atmosphere, and the small distinction between cusp and cleft cannot be determined in optical data (Moen et al., 1998). Hence we refer to this as cusp/cleft aurora.

\subsection{Variations with the orientation of the IMF}

The latitude of the cusp/cleft aurora is known to vary with the orientation of the IMF; specifically, it lies further equatorward when the IMF $B_{z}$ component (in GSM coordinates) is negative (Vorobjev et al., 1975; Horwitz and Akasofu, 1977; Sandholt et al., 1992). This "erosion" effect matches the behaviour seen by particle detectors on low-altitude spacecraft (Burch, 1973; Newell et al., 1989) and is explained by the more rapid reconnection during southward IMF at lower magnetopause latitudes, converting closed to open flux faster than they can be convected poleward.

Transient events in the cusp/cleft aurora have been shown to migrate poleward when the IMF points southward (Sandholt et al., 1992) but equatorward when it points northward (Sandholt, 1991; Øieroset et al., 1997). The poleward-moving events are seen to form in regions where the precipitation is classed as cleft and migrate into the cusp and mantle regions, consistent with the evolution of patches of newly opened flux (Moen et al., 1996; Lockwood and Moen, 1996). The equatorward-moving events that are seen when the IMF is northward behave in a way that strongly suggests that they are patches of open flux that has recently been reconfigured by lobe reconnection (Øieroset et al., 1997; Lockwood and Moen, 1999).

Statistically the cusp/cleft region is somewhat wider in latitude when the IMF points northward (Newell and Meng, 1987; Carbary and Meng, 1988). This can be explained by the generation of overdraped lobe field lines by reconnection at the edge of the tail lobe. Significant magnetosheath plasma is free to precipitate down these while they still thread the dayside magnetopause. This may cease because these field lines are returned to the tail lobe by the magnetosheath flow. However, Lockwood and Moen (1999) have found evidence that these overdraped field lines are sometimes closed by reconnection in the lobe magnetopause in the opposite hemisphere, making the cusp narrower in latitudinal width. 


\subsection{The cleft for northward IMF}

If the cleft/LLBL is indeed on open field lines, its persistence during the period of northward IMF must be explained. One possibility is that "subsolar" reconnection (here meaning anywhere between the magnetic cusps such that closed field lines are opened) can take place even when the IMF points northward. Despite the problems with understanding how the reconnection geometry can exist at a magnetopause with such low magnetic shear, this has been postulated as the best explanation of the particle distribution functions (both ions and electrons) seen at the magnetopause (Onsager and Fuselier, 1994; Fuselier et al., 1995; Chandler et al., 1999). A possible explanation was put forward by Anderson et al. (1997) in terms of the draping of a weakly northward IMF in the plasma depletion layer just outside the magnetopause.

Hall et al. (1991) find that the counter-streaming electrons that are often used to define the LLBL are present almost all the time on most of the dayside magnetopause. Lockwood and Hapgood (1997, 1998) have used the ion observations and tangential stress balance tests to show that they are well explained as being the response of the electron gas to ion flight time effects, required to maintain quasi-neutrality on newly opened field lines. The fact that these electron streams are seen during both southward and northward IMF therefore implies that reconnection is nearly always taking place somewhere on the magnetopause and is able to coat most of the boundary with newly reconnected field lines and thus counter-streaming injected sheath electrons.

Recent work shows that if the IMF vector has a northward component but lies with about $45^{\circ}$ of the magnetic equatorial plane, the cusp/cleft aurora bifurcates into two bands (Sandholt et al., 1996, 1998a, b, 2000; Lockwood and Moen, 1999). The higher latitude part is consistent with the reconfiguration of "old" open flux by reconnection at the lobe magnetopause. There are two possible origins of the lower latitude band: it could be the signature of a closed northward-IMF LLBL or it could originate from soft particle precipitation on field lines which have been opened by continuing subsolar reconnection (the type 1 aurora of Sandholt et al., 1996), despite the northward IMF component. In this paper, we present evidence that the latter process can indeed occur.

\section{Experimental configuration}

On December 16th 1998, the EISCAT Svalbard radar was operated from 05:00 to 13:00 UT. The radar is located close to Longyearbyen (geographic coordinates $78.20^{\circ} \mathrm{N}$ and $15.82^{\circ} \mathrm{E}$ ) and the beam was fixed in the local field-aligned direction (azimuth $180.6^{\circ}$, elevation $\left.81.6^{\circ}\right)$. The radar ran the recently developed GUP3 modulation scheme which combines both plain and phase-coded pulses to make measurements over a continuous range of altitudes from 90 to $1000 \mathrm{~km}$. A clutter cancellation technique is used, which employs pairs of pulse codes whose spacing is longer than the correlation time of the observed plasma waves, but less than the correlation time of the surrounding mountains. In this way, unwanted echoes which arise from the local relief up to a range of about $150 \mathrm{~km}$ are removed from the data, so that only the ionospheric contribution remains. By using the Finnish GUISDAP analysis programme, the ESR data have been analysed in such a way that the altitude resolution at any given height corresponds closely to the ionospheric scale height in that region.

At the same time, the EISCAT VHF radar in Tromsø (geographic coordinates $69.59^{\circ} \mathrm{N}$ and $19.23^{\circ} \mathrm{E}$ ) was operated in the "CP-4" mode, which employs two beams, both pointed at $30^{\circ}$ elevation. One beam is pointed towards magnetic north so that it is normal to the magnetic L-shells (azimuth $1,15^{\circ}$ west of geographic north) and the other beam towards the ESR (azimuth 2, $0.5^{\circ}$ west of geographic north), giving a separation of $14.5^{\circ}$ between the two beams. Plain long pulses are used to obtain data at ranges between 600 and $1600 \mathrm{~km}$, giving a coverage that extends well beyond the latitude of the ESR field line (at a range of $1100 \mathrm{~km}$ from Troms $\varnothing$ ). In this kind of combined experiment, the VHF results are very useful as they allow the ESR data to be placed in a wider latitudinal context. Further details of these two radars and of the incoherent scatter technique are given in the review by McCrea and Lockwood (1997).

Further very important measurements for determining the latitudinal context of the radar results were made using the two meridian scanning photometers (MSP) at Longyearbyen and $\mathrm{Ny}$ Ålesund $\left(78.92^{\circ} \mathrm{N}\right.$ and $\left.11.95^{\circ} \mathrm{E}\right)$. These instruments detect optical emissions at frequencies of $630.0 \mathrm{~nm}$ and $557.7 \mathrm{~nm}$, the red- and green-line auroral emissions from excited atomic oxygen, which mainly arise from F- and E-region altitudes, respectively. Both instruments scan in the geomagnetic meridian. The parameters of the scan are adjustable, but during most of the interval discussed here, the Ny Alesund MSP scanned from elevations of $20^{\circ} \mathrm{N}$ to $20^{\circ} \mathrm{S}$ (zenith angles of $\pm 70^{\circ}$ ). Since the northern part of the scan from Longyearbyen overlaps with the southern part of the scan from Ny Alesund, it is possible to achieve continuous coverage of auroral emissions above Svalbard, provided that the weather is clear at both sites. The photometers scan approximately once every $20 \mathrm{~s}$.

The CUTLASS HF radars (e.g. Milan et al., 1997) located in Finland and Iceland, were operated in a special programme mode. Fourteen beam directions of the CUTLASS Finland radar were scanned every three minutes, while three beams whose pointing directions were important for the geometry of the combined experiment were sampled at high-time resolution. Beam 7 (the beam which points in the geomagnetic north direction) was sampled every nine seconds throughout the experiment. Beam 5 (pointing over Tromsø) and beam 9 (pointing over Longyearbyen) were sampled every nine seconds for two minutes in every three (the 
remaining minute being used to do the fourteen-beam scan). Along each beam direction, 75 range gates were sampled, giving range gates $45 \mathrm{~km}$ long and data coverage from 180 to $3555 \mathrm{~km}$ range. Because of uncertainties in the HF ray path between the radar and the scattering region, the relationship between ground range and slant path range cannot be determined precisely. The altitude of the scattering region is not accurately known and since the slant range of the measurement depends upon its altitude, the precise identification of the scattering region around the ESR beam is not possible. Due to HF absorbtion, little useful data were obtained from the Iceland radar, but the Finland radar observed strong backscatter.

Data from two spacecraft have also been used in this study. On December 16th 1998, the WIND spacecraft was on the dayside of the Earth in the northern hemisphere just outside the bow shock $\left(Y_{G S E}=26\right.$, $X_{G S E}=4, Z_{G S E}=27 R_{E}$, where a mean Earth radius, $\left.1 R_{E}=6370 \mathrm{~km}\right)$. Hence the spacecraft was immersed in the solar wind, and would observe changes at a time close to when they would impact on the magnetosphere and subsequently would have been manifested in the cusp/cleft ionosphere. This is true provided the interplanetary medium is uniform over the $27 R_{E}$ difference in $\mathrm{Y}$ between the Earth and WIND: smaller scale structure would mean that WIND failed to measure exactly the same conditions as impact the Earth. With this in mind, it is valuable also to study the interplanetary measurements from the ACE spacecraft close to the L1 point.

\section{Observations}

\subsection{ESR observations}

Figure 1 shows a multi-panel plot of the electron density, $N_{e}$, electron temperature, $T_{e}$, ion temperature, $T_{\mathrm{i}}$, and ion velocity, $V_{\text {para }}$, as measured by the EISCAT Svalbard radar during the interval from 06:00 to 09:00 on 16th December 1998. Note that the ion temperatures and velocities are field-aligned, with positive velocities corresponding to upward flows. The data reveal a number of distinct regions. Until about 06:30, the density profile was relatively uniform with the F2 peak near $275 \mathrm{~km}$. At these times, electron temperatures were low and there was upward field-aligned flow where the ion temperature was enhanced, but field-aligned flows became downward when the ion temperature dropped back towards exospheric values. At the end of this interval densities fell, before rising abruptly at 06:35, when electron temperatures are more than doubled. These high electron temperatures remained throughout the interval 06:35-07:00, when F2 densities were structured and the F2 peak was considerably higher (about $400 \mathrm{~km}$ ) than before. Elevated ionospheric electron temperatures of this magnitude are seen in the cusp/ cleft region by low-altitude satellites (Curtis et al., 1982) and have been detected by incoherent scatter radar in association with cusp/cleft particle precipitation (e.g. Watermann et al., 1992, 1994). High and structured ion temperatures were seen in this interval and field-aligned flows were uniformly upward. The observations during this period are discussed in detail by Lockwood et al. (2000) and Thorolfsson et al. (2000) (both papers in this issue). In the interval 07:00-07:50, densities were very low; electron temperatures were structured but generally lower. Again flows were initially upward where ion temperatures were high but turned to strongly downward as the ion temperature subsequently fell. After 07:50 densities recovered but were structured, as were electron temperatures. Ion temperatures remained low and field-aligned flows were downward. Around 08:00 were the only upward flows that were not accompanied by high ion temperatures. Representative density profiles observed by the ESR during this extended interval are shown and discussed by Lockwood et al. (this issue).

\subsection{EISCAT VHF observations}

Figure 2 shows a similar plot for the data obtained from azimuth 2 of the VHF radar (the beam that lies closest to Svalbard). We only present data from this beam as the other VHF beam gave very similar results. In interpreting Fig. 2, it must be remembered that latitudinal variations are convolved with altitude profiles. However, the ESR data suggest that altitude variations in electron and ion temperatures were relatively small above about $350 \mathrm{~km}$, implying that the structures in $T_{e}$ and $T_{i}$ seen in the VHF data at greater ranges were mainly due to latitude variations. In these two panels we see a region of higher temperatures moving closer to the radar between about 06:30 and 07:20, showing that it was migrating equatorward. The onset of high electron and ion temperatures at the ESR field line at 06:30 is seen to be caused by the equatorward motion of this band of high $T_{e}$ over the ESR. A region of structured, but somewhat lower, electron temperature migrated over the ESR shortly after 07:00. Data were lost between 07:20 and 07:40 due to a brief transmitter failure, and it seems likely that in this interval the elevated electron temperatures reached their greatest southward extension. At about 07:50, the band of high electron temperature moved poleward back over the ESR, and by this time the ion temperatures had decreased at all latitudes. Around 08:15 the band was observed to bifurcate. The northern part of the band of high electron temperature continued to retreat poleward, while the southern region of high $T_{e}$ once again proceeded equatorward until it was centred at around $800 \mathrm{~km}$ range from Tromsø (see the second panel of Fig. 2). Between the two regions (at about $1000 \mathrm{~km}$ range) was a region of lower electron temperature $(<2500 \mathrm{~K})$ and the ESR emerged into this gap near 08:30.

Thus the electron temperature data seen by the ESR can be understood in terms of the latitudinal structure and motions detected by the VHF radar. The ion temperatures seen by the ESR are explained by an equatorward motion of a region of enhanced ion temperature which paralleled that in the electron tem- 

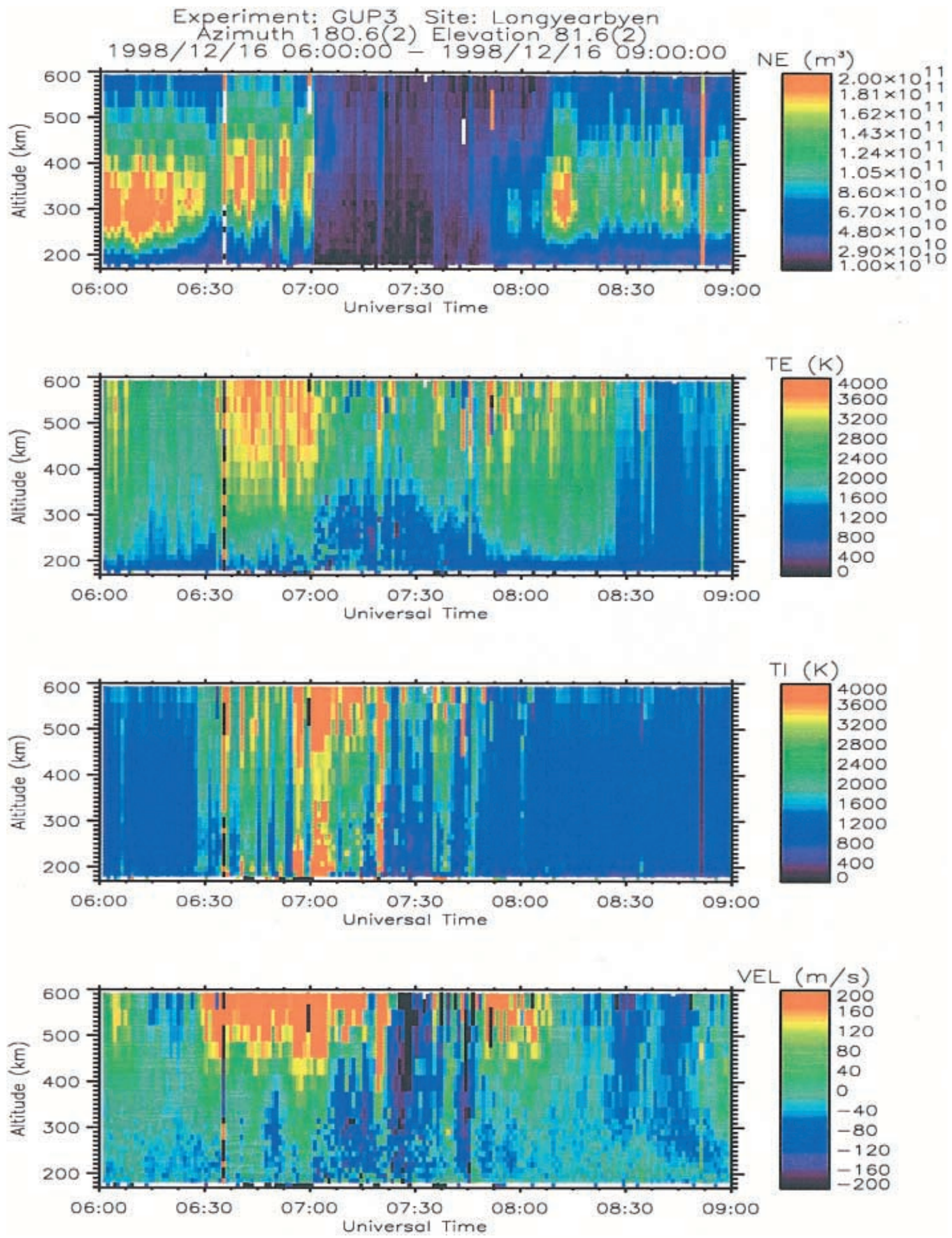

Fig. 1. Multi-panel plot showing the variation of (from top to bottom) electron density, $N_{e}$, electron temperature, $T_{e}$, field-parallel ion temperature, $T_{i}$, and field-aligned velocity, $V_{\text {para }}$, with height and

perature; however, the poleward retreat of the band of high electron temperatures was accompanied by a fall in ion temperatures at all latitudes. The fluctuations in ion temperature reveal enhanced and structured field-perpendicular convection which raised $T_{i}$ by ion-neutral frictional heating (McCrea et al., 1991; Davies et al., 1997). Although this process preferentially raises the time, derived from the long pulse part of the ESR GUP3 experiment of the ESR on December 16th 1998

field-perpendicular ion temperature (Winser et al., 1987), the field-aligned value also increases considerably (McCrea et al., 1993).

A common procedure when working with data from the two beams of the VHF radar is to use the line-ofsight velocities, measured simultaneously at various ranges in each of the two directions, to produce a map of 

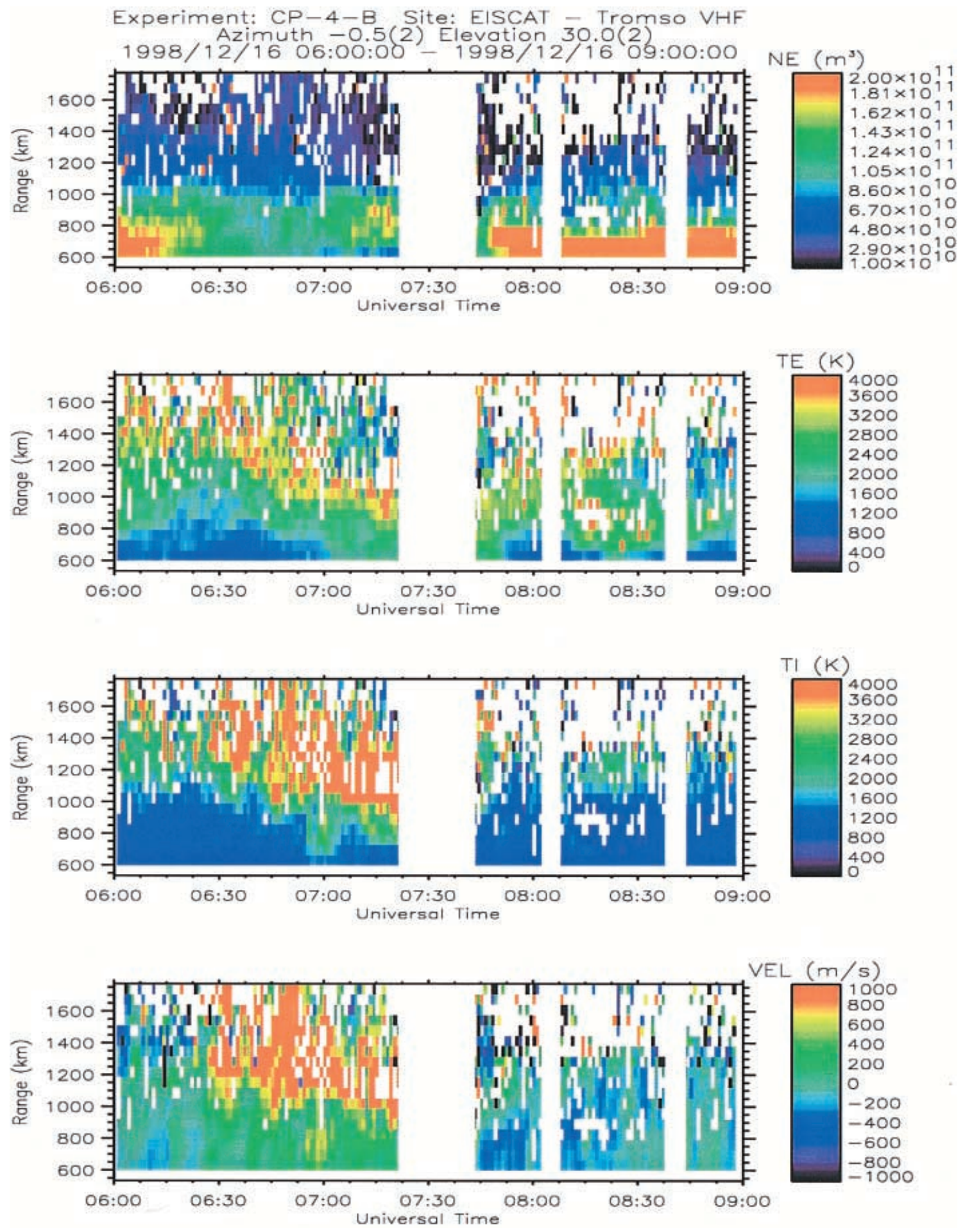

Fig. 2. Multi-panel plot showing the variation of (from top to bottom) electron density, $N_{e}$, electron temperature, $T_{e}$, line-of-sight ion temperature, $T_{l o s}$, and line-of-sight velocity, $V_{l o s}$, with range and

the plasma velocity field to the north of EISCAT. In this "dual-beam" method (Lockwood et al., 1993), a variation of the "beam-swinging" technique, the velocities are matched from points where each beam crosses the same L-shell. The implicit assumptions are that the fieldaligned plasma velocity is insignificant compared to the field-perpendicular component and that the velocity time, derived from the long pulse CP-4 experiment of the EISCAT VHF radar on December 16th 1998

field is homogeneous over the distance between the beams. These assumptions become increasingly unreliable as the invariant latitude increases (Etemadi et al., 1989; Freeman et al., 1991). Thus the field-perpendicular vectors shown in Fig. 3 can be used only as an indication of the general convection flow speeds and directions. Note, however, with the assumption that the 

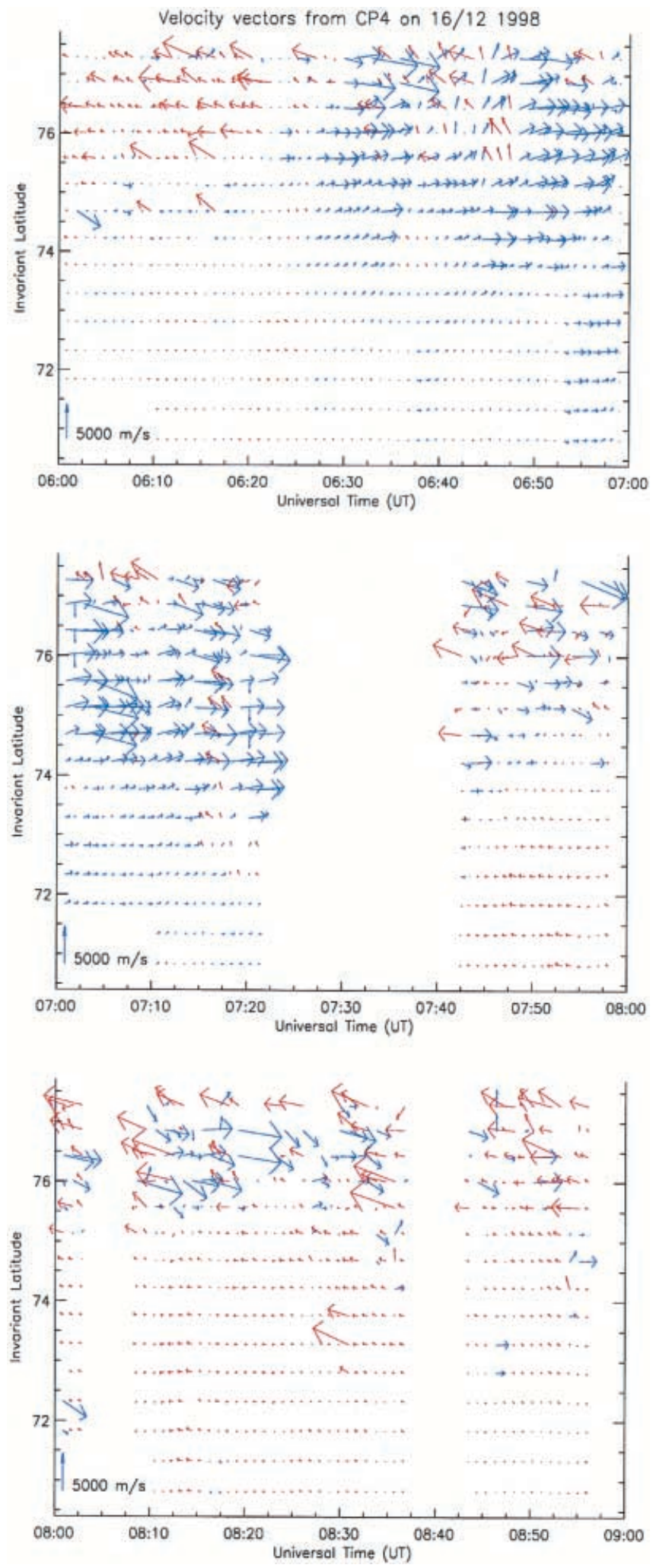

Fig. 3. Vector plots showing the variation of plasma velocity derived from the $V_{\text {los }}$ measurements by the EISCAT VHF data using the dual-beam technique, as a function of time and invariant latitude for December 16th 1998. Eastward flow vectors are coloured blue, westward are coloured red. Note that the north-south component is directly measured by the radar in azimuth 1 field-parallel flows are negligible, that azimuth 1 observes the northward component directly.

Figure 3 shows the velocity field derived from the dual-beam technique during the interval covered by Figs. 1 and 2. From 06:00 to 06:20 UT, the velocities measured close to EISCAT were very small. Larger convection flows only appeared poleward of $\Lambda=75^{\circ}$ and derived vectors were all directed towards the west (westward flows are coloured red, eastward flows blue). Around 06:30 UT, however, the flow reversed in direction, turning eastward and becoming detectable at somewhat lower latitudes. Within this interval of generally eastward velocity, the ESR observed the series of transient increases in ion temperatures shown in Fig. 1. This pattern of eastward flow continued until 07:20 UT, when the transmitter break made any determination of the velocity impossible until 07:45 UT. By this time, the field-perpendicular flows had returned to being small around the ESR. The data at higher latitudes were too disordered to give any clear impression of the general orientation of the flow northward of about $\Lambda=74^{\circ}$.

Note that very few vectors were consistently southward. This is significant, given that this component was directly measured by azimuth 1 of the VHF. Weak equatorward convection flows were only seen at about 07:45-07:50, poleward of $\Lambda=75^{\circ}$.

\subsection{Magnetometer observations}

Figure 4 shows the variations in the horizontal component of the field, $\mathrm{H}$, seen by a network of magnetometers around the ESR. Dashed lines indicate the undisturbed level of the H-component for each magnetometer. All stations showed decreases in $\mathrm{H}$ between 06:30 and 07:30, in response to the southward IMF. This is consistent with enhanced westward Hall currents and the eastward convection flow, as deduced from the VHF radar by the dual-beam method. The bursts of high $T_{i}$ seen by the ESR were accompanied by only small fluctuations in $\mathrm{H}$ because conductivities were low in these dark conditions.

\subsection{Optical observations}

Figures 5 and 6 show the data from the meridian scanning photometer (MSP) at Ny Alesund. Unfortunately, skies over Longyearbyen were partially cloudy and only intermittent data were obtained from the MSP there. The instrument scans in the meridian plane from about $20^{\circ}$ elevation to the south (to the right in each panel) to $20^{\circ}$ elevation to the north (to the left), taking about $20 \mathrm{~s}$ to complete a scan. It is sensitive to wavelengths of $630.0 \mathrm{~nm}$ and $557.7 \mathrm{~nm}$, corresponding respectively to the red and green lines of emission from excited states of atomic oxygen (shown in the left and right hand panels). Time runs from top to bottom of each panel. 


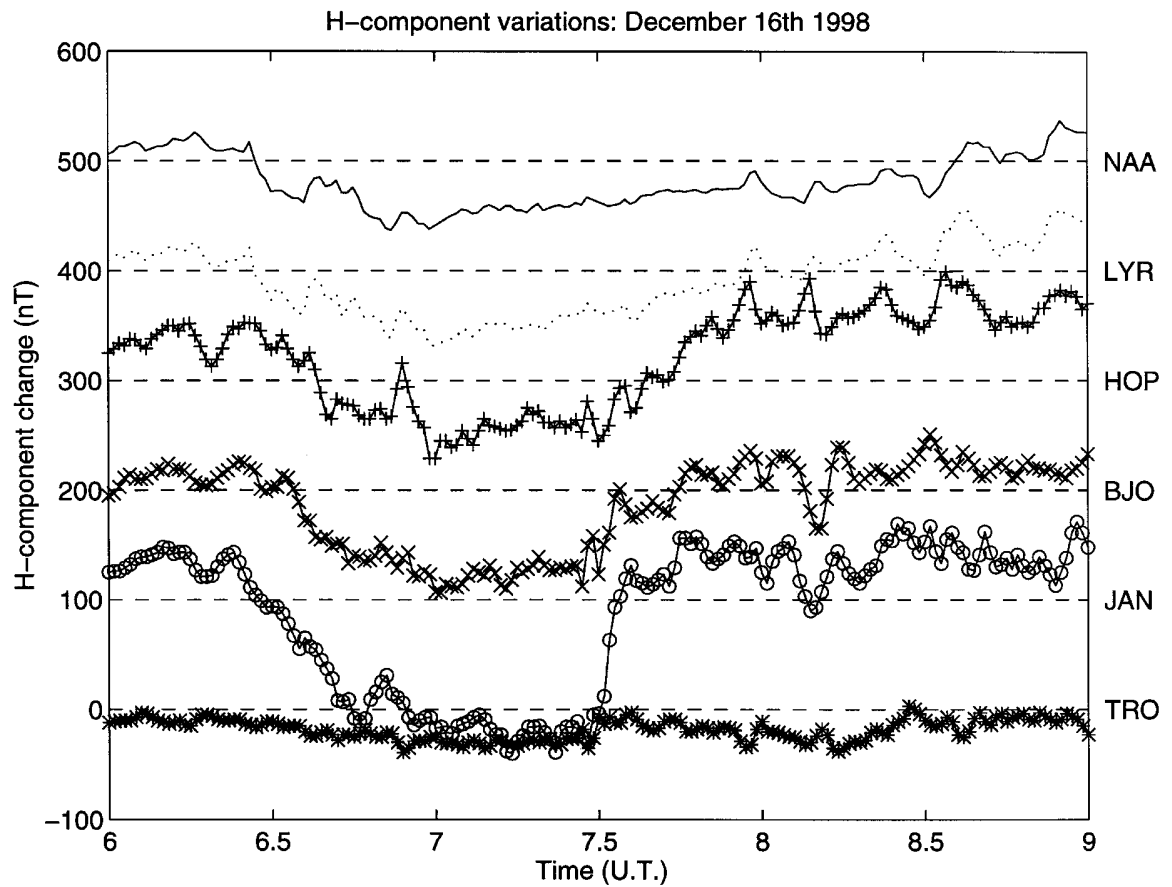

Fig. 4. Horizontal components $(\mathrm{H})$ of the magnetic field detected by ground-based magnetometers around the ESR. From north to south, the magnetometers are located at $\mathrm{Ny}$ Ålesund ( $N A A$, geographic coordinates $\left.78.92^{\circ} \mathrm{N}, 11.95^{\circ} \mathrm{E}\right)$, Longyearbyen $\left(L Y R, 78.20^{\circ} \mathrm{N}, 15.82^{\circ} \mathrm{E}\right)$, Hopen $\left(H O P, 76.51^{\circ} \mathrm{N}, 25.03^{\circ} \mathrm{E}\right)$, Bjørnøya $(B J O$ $\left.74.50^{\circ} \mathrm{N}, 19.00^{\circ} \mathrm{E}\right)$, Jan Mayen $(J A N$, $70.90^{\circ} \mathrm{N}, 351.30^{\circ} \mathrm{E}$ and Tromsø (TRO, $\left.69.59^{\circ} \mathrm{N}, 19.23^{\circ} \mathrm{E}\right)$
The L-shell of the ESR intersects the meridian scanned by the MSP roughly $100 \mathrm{~km}$ equatorward of Ny Ålesund. The zenith angle of emissions from along the ESR beam will depend on their altitude and values of $45^{\circ}, 24^{\circ}, 20^{\circ}$ and $18^{\circ}$ apply to emission altitudes of $120 \mathrm{~km}, 300 \mathrm{~km}, 400 \mathrm{~km}$ and $500 \mathrm{~km}$, respectively. The green-line emission is believed to come from near $120 \mathrm{~km}$ altitude, although Sigernes et al. (1996) have reported heights up to $150 \mathrm{~km}$. Red-line emission extends between about 250 and $500 \mathrm{~km}$. Figure 1 shows that $N_{e}$ peaked near $400 \mathrm{~km}$ when the ESR was in the cusp/cleft region. Davis and Lockwood (1996) found peak $N_{e}$ volume emission rates were at similar altitudes and so we here assume the latter is at $400 \mathrm{~km}$. The approximate location of the ESR is shown by a vertical line on each plot, based on assumed peak emission altitudes of $400 \mathrm{~km}$ and $120 \mathrm{~km}$ for the red and green lines respectively.

The MSP data show very clearly the way in which the auroral precipitation evolved during the interval corresponding to the radar data and show many of the same features as the electron temperature data from the VHF radar. At 06:10-06:30 UT, auroral emissions were characterised by disordered red line mainly to the north of $\mathrm{Ny}$ Ålesund, with little corresponding green-line emission. The green-line emission, although much weaker than the red line, showed very similar behaviour to the red line throughout. The high ratio of the red and green emission line intensities was typical of the cusp/ cleft aurora. After about 06:30 UT a clear change occurred, with the red-line emission becoming much more localised in latitude and moving steadily equatorward. Enhanced emission from near the ESR began at about 06:35. Continuously enhanced (but highly structured) emission from the vicinity of the ESR ceased around 06:48, when the cusp/cleft aurora moved equatorward of it. Subsequently, two poleward-moving transient events were seen and enhanced emission intersected the approximate ESR location at 06:5106:53 and 06:57-07:01 UT. In the second event a strong peak was seen near the ESR at 06:59. These events are discussed in more detail by Lockwood et al. (2000) and Thorolfsson et al. (2000), both papers in this issue.

The greatest extent of this southward expansion was reached at around 07:30 UT with the red-line emissions well south of the ESR, after which the main red-line (and the weaker green-line) emissions retreated steadily back towards the latitude of Ny Ålesund. This main band of red-line emission moved poleward of the ESR by $08: 30$. Figure 6 shows, however, that some weak redline emission still remained equatorward of the ESR. This emission was intermittent and weaker than the redline aurora seen further north, but its presence was clearly seen at the southern edge of the MSP viewing area at around 08:15 and after 08:30 UT. This weak band of remnant emission occurred at the same time as the bifurcation seen by the VHF radar in the band of enhanced electron temperatures, described in section 3.2. The main band of cusp/cleft aurora was much less structured as it returned northward. One enhancement of the $630 \mathrm{~nm}$ aurora was seen near the ESR at 08:0408:06 and corresponded to the pulse of enhanced $N_{e}$ seen by the radar at this time (Fig. 1). The associated $557.7 \mathrm{~nm}$ emission appeared to be well poleward of the red-line emission, indicating that it arose from an altitude considerably greater than the $120 \mathrm{~km}$ assumed in plotting the ESR location.

\subsection{CUTLASS observations}

The CUTLASS data show a very striking agreement with the data from the EISCAT VHF radar. Figure 7a shows the spectral widths observed in the CUTLASS 

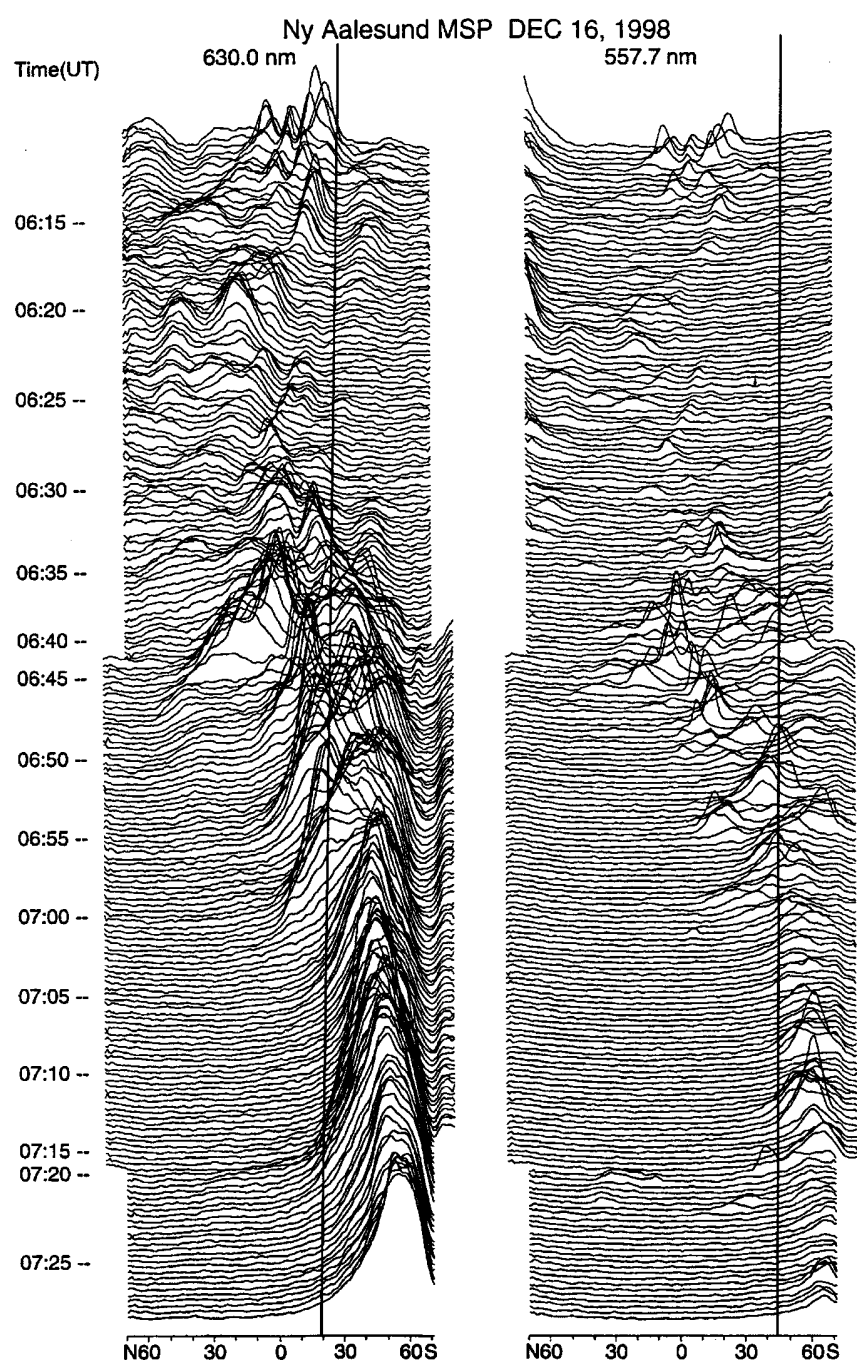

Fig. 5. Data from the Ny Ålesund MSP, showing the distribution of red-line $(630.0 \mathrm{~nm}$, left) and green-line $(557.7 \mathrm{~nm}$, right) emissions as a function of zenith angle in the north-south meridian from 06:10 UT to 07:30 UT on December 16th 1998. Northward is to the left of each panel and time runs down. Vertical lines on each plot show the elevation corresponding to emissions from the ESR field line at $400 \mathrm{~km}$ and $120 \mathrm{~km}$ for the red and green lines, respectively

Finland data as a function of magnetic latitude, and these exhibit a very similar behaviour to the band of enhanced electron temperature observed by the VHF radar and shown in Fig. 2. A region of backscatter echoes with high spectral width was observed, initially at the northern edge of the scattering region, and migrated equatorward until about 07:30 UT, by which time it had reached a magnetic latitude of some $73^{\circ}$ (equivalent to $900 \mathrm{~km}$ range from Troms $\varnothing$ ). This region is also extremely well correlated with the region of $630 \mathrm{~nm}$ optical emission observed by the meridian scanning photometer. After 07:30, the feature began steadily to retreat poleward. However a remnant area of backscatter with high spectral width, best seen in beams 7 and 9, remained at a magnetic latitude of $72^{\circ}$, separated from the northern branch by a region with smaller spectral widths, centred around $73.5^{\circ}$. The morphology of these regions was identical to the region

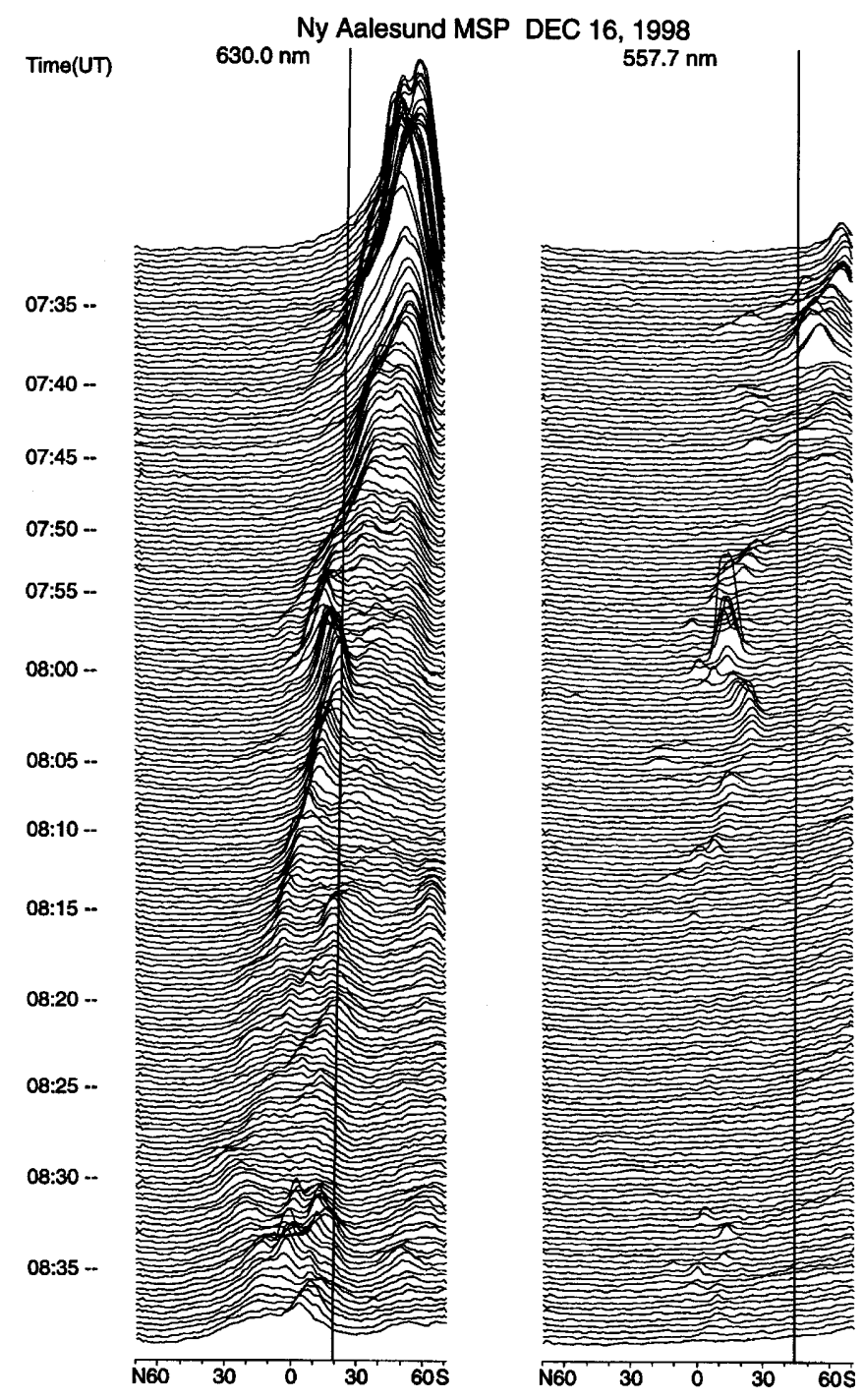

Fig. 6. As for Fig. 5, but for 07:30 UT to 08:40 UT on December 16th 1998

of enhanced electron temperature shown in the second panel of Fig. 2.

Although a complete understanding of the phenomenon is still lacking, there is a consensus that regions in which the width of the HF radar backscatter spectrum exceeds some $150 \mathrm{~ms}^{-1}$ can be identified as signatures of cusp field lines (e.g. Baker et al., 1995). It therefore seems that the CUTLASS data support the observations of the EISCAT VHF radar and meridian scanning photometer in showing an expanding area of cusp/cleft aurora during $B_{z}$ south conditions until 07:30 UT. This was followed by a poleward retreat as $B_{z}$ turned northward, with the cusp/cleft aurora finally bifurcating to leave a remnant area at around $72^{\circ}$ magnetic latitude, isolated by some $3^{\circ}$ from the retreating northward branch of high electron temperature and spectral width.

The CUTLASS velocity data are also consistent with the EISCAT VHF measurements. In Fig. 7b, one can see that the flows in beam 9 (the direction towards Longyearbyen) agreed well with the line-of-sight velocities 


\section{SUPERDARN PARAMETER PLOT 16 Dec $1998^{(350)}$}

\section{Finland: width_l}

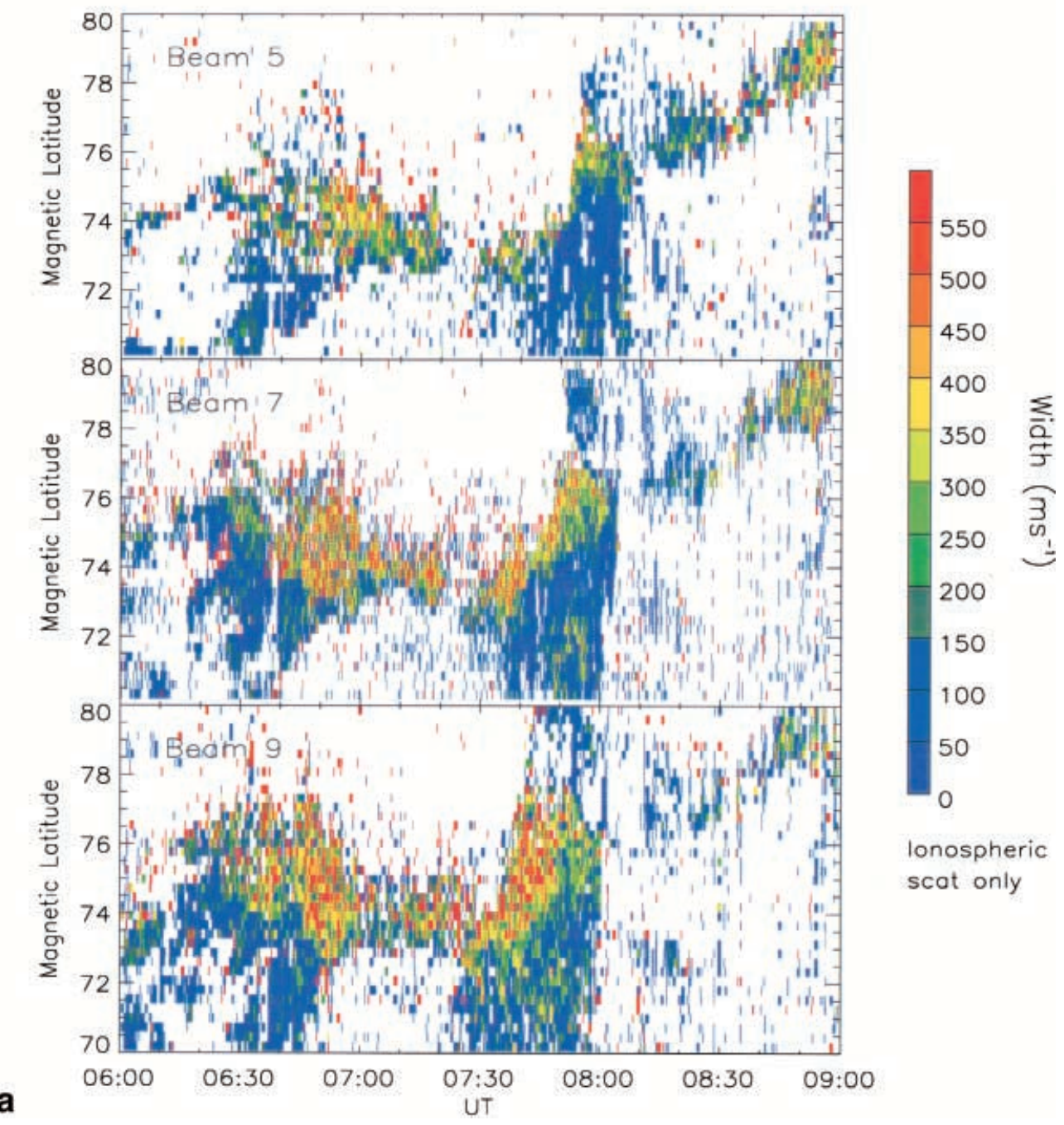

Fig. 7a.

measured by the VHF radar and shown in the bottom panel of Fig. 2. In this plot the velocity has been inverted from the normal CUTLASS sign convention, so that positive velocities correspond to convection away from the radar, as in the EISCAT plots. As in the EISCAT VHF data, flow away from the radar was observed throughout the interval of $B_{z}$ south, but when $B_{z}$ turned northward and the region of cusp-type backscatter began to retreat poleward, no strong flow was seen in either direction. This corresponded to the time when the vectors derived by the VHF dual-beam velocity technique (Fig. 3) implied flows which were disordered, with a tendency for weak sunward flow to predominate, as opposed to the anti-sunward flow seen during the interval of $B_{z}$ south.

\subsection{Interplanetary observations}

Figures 8 and 9 show data from the ACE and WIND spacecraft during the early part of December 16th 1998.
ACE was located close to the L1 point, about one million kilometres upstream from the Earth on the SunEarth line, while WIND was located at high northern latitudes just outside the bow shock. Based on these locations and the observed solar wind flow speed, the expected delay times for the IMF observed by ACE and WIND to reach the Earth would have been about $65 \pm 5 \mathrm{~min}$ and $1 \pm 5 \mathrm{~min}$, respectively. The ACE data are valuable in that WIND is at a relatively large distance from the Earth in the $\mathrm{Y}-\mathrm{Z}$ plane. This opens up the possibility of it detecting solar wind and IMF structure that do not impinge upon the Earth. The ACE and WIND data are used together here to establish the coherence of the IMF structure and to confirm that the WIND results were representative of the variations in the IMF.

The ACE and WIND IMF data provide a consistent explanation for the expansion of the auroral emissions and the associated activity. Before 05:00 UT, the IMF $B_{z}$ observed at ACE was generally northward, at times reaching values in excess of $10 \mathrm{nT}$. A sharp southward 


\section{SUPERDARN PARAMETER PLOT 16 Dec $1998^{(350)}$}

\section{Finland: vel}

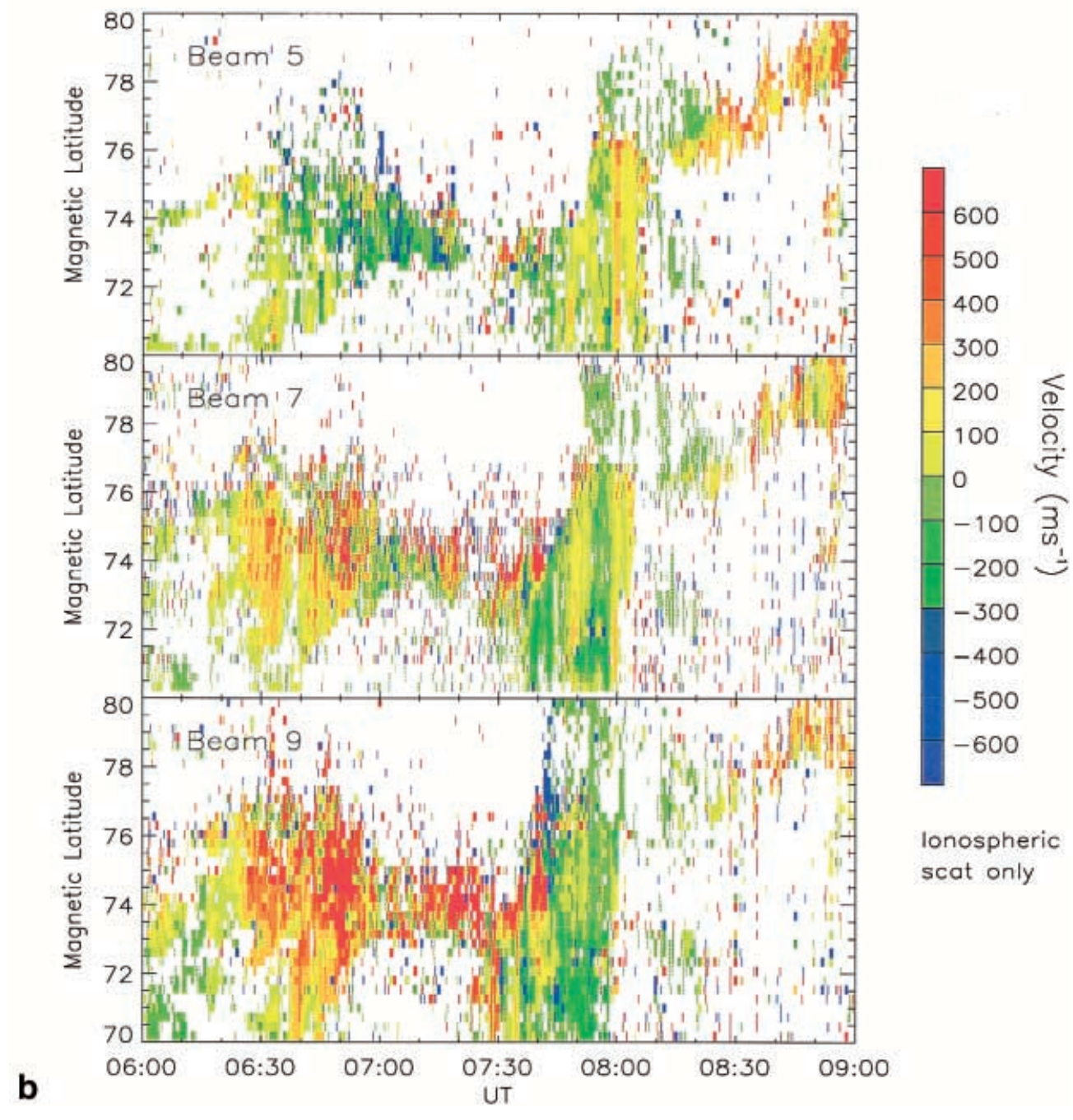

Fig. 7. a Panel plot showing CUTLASS Finland spectral widths from December 16th 1998 for beam 5 (looking over Tromsø), beam 7 (pointing geomagnetic north) and beam 9 (pointing over Longyearbyen). The area of high spectral width $\left(>200 \mathrm{~ms}^{-1}\right)$ is believed to correspond to field lines associated with the cusp. b CUTLASS Finland line-of-sight velocities from beam 5, beam 7 and beam 9. The sign convention of the velocities has been changed to match that of the EISCAT data (positive velocities mean motion away from the radar)

turning of the IMF was then seen - first at around 05:15 UT by ACE and then around 06:15 by WIND. The IMF reached about $-6 \mathrm{nT}$ and remained steady for a period of around one hour. Then the IMF returned to a northward orientation, the transition being observed at around 06:30 by ACE and 07:30 UT by WIND. The time of the southward turning in the IMF seen by WIND thus agreed very closely with the time at which the auroral oval began its expansion. Furthermore, the timing of the subsequent northward turning in IMF was shortly before the start of the poleward retreat of the main aurora, which led to the bifurcation of the bands of enhanced electron temperature and cusp/cleft aurora. It was also shortly before the decay in ion temperatures.

Whenever the IMF was northward $\left(B_{z}>0\right)$, the $\mathrm{X}$ component, $B_{x}$, was positive and $B_{y}$ was near zero. Following the southward turning, $B_{x}$ was generally negative and $B_{y}$ fell to near $-7 \mathrm{nT}$, although it rose slightly to $-5 \mathrm{nT}$ around 06:50. Both $B_{x}$ and $B_{y}$ were thus of similar magnitudes during the interval when $B_{z}$ was southward, while $B_{x}$ was of greater magnitude than $B_{y}$ for the interval of northward $B_{z}$.

\section{Discussion}

The data shown in the previous section reveal a number of interesting features. Here we discuss how the overall morphology of the cusp/cleft precipitation and the convection flows responded to the IMF changes. We also look at the nature and causes of the field-aligned plasma upflows in and around the cusp/cleft which feed the cleft ion fountain. The cusp/cleft region seen during southward IMF was highly structured, in a way that is similar, but somewhat more complex, than predicted for pulsed magnetopause reconnection by Davis and Lockwood (1996). Much of the additional structure appeared to be caused by fast convection flow bursts and these were largely absent when the cusp/cleft passed poleward 

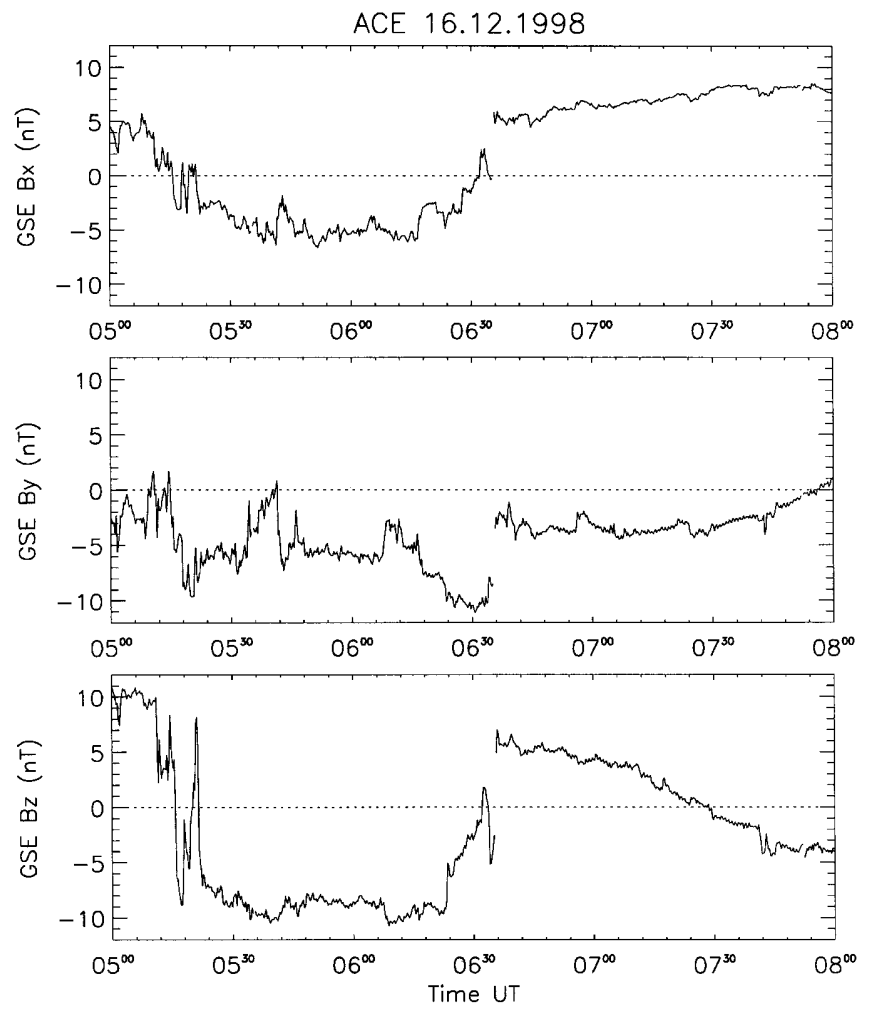

Fig. 8. Components of the Interplanetary Magnetic Field (in GSE coordinates) on December 16th 1998, as measured by the ACE spacecraft at the L1 point

over the ESR after the subsequent northward turning of the IMF. In the ESR measurements made to date, structure of this kind has been a common feature of the cusp/cleft region (Sedgemore-Schulthess et al., 1999). Two companion papers in this issue (Lockwood et al., 2000 and Thorolfsson et al., 2000) study this cusp/cleft intersection in greater detail.

\subsection{The response of the cusp location and flows to the IMF variations}

Interpretation of the ESR radar data alone would have been impossible. However, the wealth of supporting diagnostics which were available have enabled us to reach an explanation for what occurred during the interval 06:00 to 08:00 UT on December 16th 1998. At the beginning of the period, the IMF $B_{z}>0$ and auroral activity was initially confined well to the north of Svalbard. The VHF radar observed westward convection poleward of $\Lambda=76^{\circ}$, with no significant flow further south. We can explain the cusp precipitation and convection as resulting from lobe reconnection, as shown in Fig. 10a.

Lobe reconnection during northward IMF in the local hemisphere is expected to drive sunward convection flows (Maezawa, 1976; Burke et al., 1979; Zanetti et al., 1984; Cumnock et al., 1992; Freeman et al., 1993). However, Crooker and Rich (1993) found that this is largely a summer phenomenon and invoked the
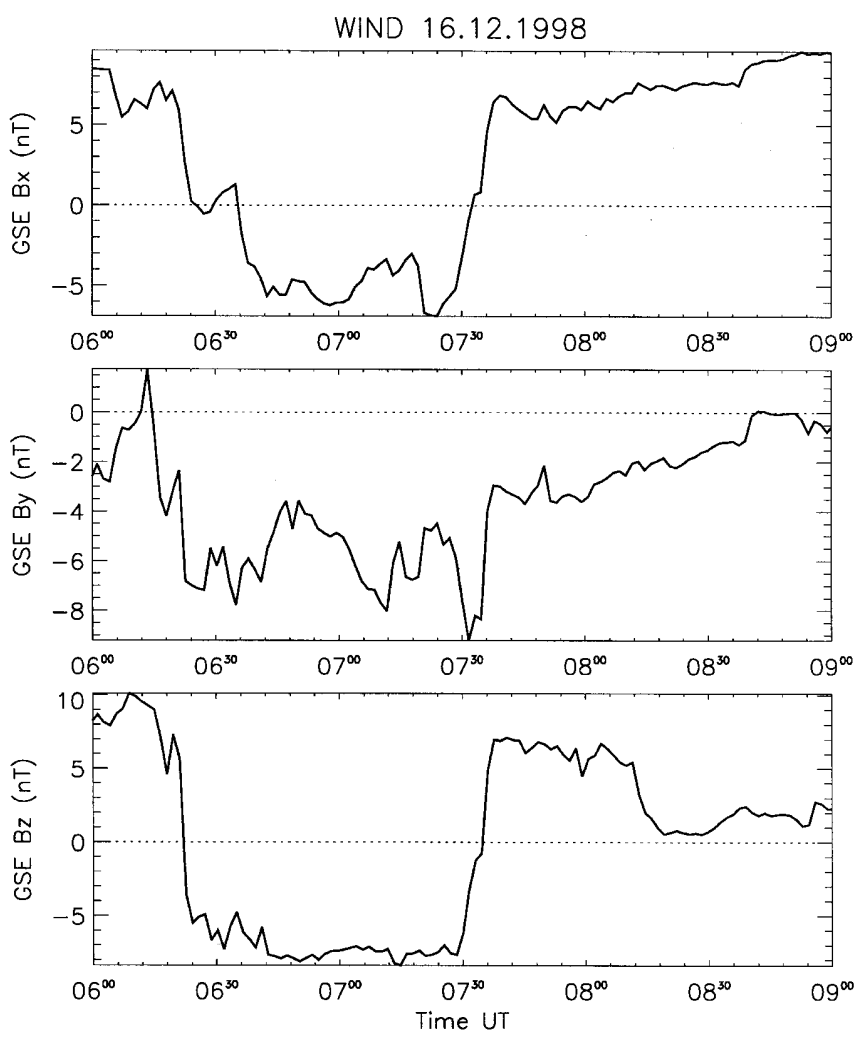

Fig. 9. As for Fig. 4, but showing the IMF components measured by the WIND spacecraft near Earth

Earth's dipole tilt as an explanation. Because our observations were made at winter solstice, the magnetic field in the cusp and mantle was tipped away from the sun and this may have limited the occurrence of lobe reconnection. This effect is apparent in the studies by Freeman et al. (1993) and Knipp et al. (1993). Lockwood and Moen (1999) argued that the IMF $B_{x}$ component would be able to overcome this dipole tilt bias. Lobe reconnection reconfigures already open flux such that it threads the dayside magnetopause, allowing high density sheath plasma access to the magnetosphere and upper atmosphere and so generating cusp aurora. These reconfigured field lines were termed "overdraped lobe" by Crooker (1992) because they are initially draped over the dayside magnetosphere. Lockwood and Moen (1999) have discussed their subsequent evolution.

However, in the data shown here, northward IMF was accompanied by positive $B_{x}$, an orientation which Lockwood and Moen (1999) argue favours lobe reconnection in the southern, rather than the northern, hemisphere. The effects of this type of southern hemisphere reconnection on convection in the northern polar cap have recently been reported by Maynard et al. (2000). Figure 10a shows that at least some of the westward convection could have resulted from polar cap contraction due to some continuing reconnection in the tail current sheet, as suggested by Lockwood and Cowley (1992) and observed during weak northwardIMF substorms by Fox et al. (1994). However, this would cause eastward convection also to be seen at 
a). 06:15 U.T. $B_{z}=+9 n T ; B_{y}=+2 n T$

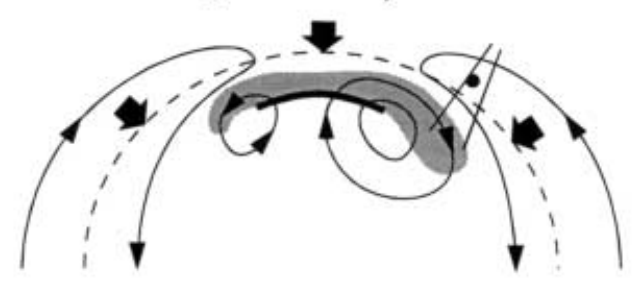

b). 06:45 U.T. $B_{z}=-7 n T ; B_{y}=-6 n T$

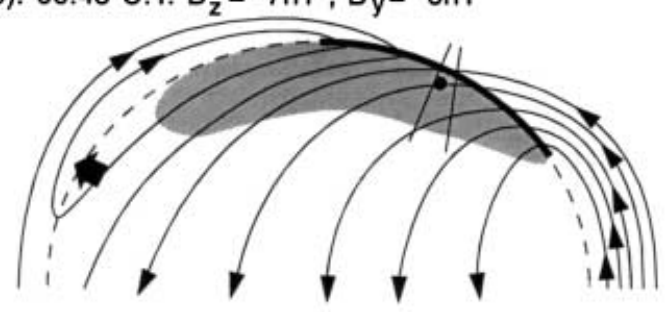

c). $07: 15$ U.T. $B_{z}=-7 n T ; B_{y}=-9 n T$

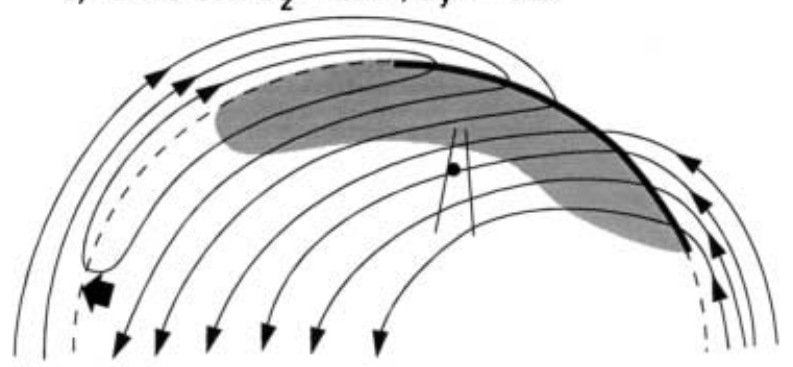

d). 08:30 U.T. $B_{z}=+1 n T ; B_{y}=-2 n T$

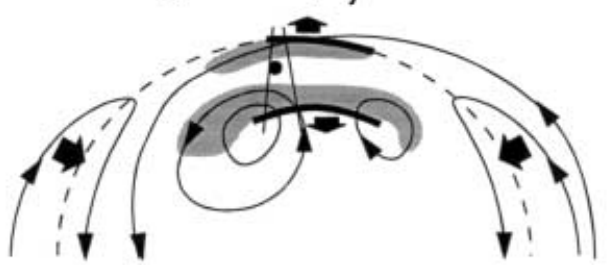

Fig. 10. Schematic illustration of the relative positions of the ESR (dot) and VHF radar beams (paired lines) the cusp/cleft precipitation on newly reconnected field lines (shaded grey) and the average convection flow streamlines. Non reconnecting ("adiaroic") segments of the open-closed field line boundary are shown as a dashed line and the footprints of active reconnection X-lines as thick solid lines. Large arrows show the motions of the open-closed boundary and the lobe $\mathrm{X}$-line footprint. The relevant times and prevailing IMF conditions are given for each panel

lower latitudes and this was largely absent from the data. Thus it appears lobe reconnection was taking place in the local hemisphere in this case, despite the unfavourable IMF $B_{x}$ polarity.

Around 06:20 UT, the ionosphere began to respond to the southward turning of the IMF, as seen by ACE and WIND. The convection flow reversed in direction and the region in which convection was excited began to expand, along with an expansion in the auroral oval, as seen by the MSP and the VHF radar. Field-perpendicular flows were eastward, consistent with the negative IMF $B_{y}$. A component of these eastward flows can be seen as the positive velocities (away from the radar) in the lower panel of Fig. 2, where the equatorial expansion of the flow is seen to parallel that of the electron and ion temperatures. The other VHF azimuth, being perpendicular to the L-shells, does not show such a large component of the eastward flow. The transition from initial westward flow, confined to high latitudes, to a latitudinally extended region of eastward flow is well shown by the VHF beam-swinging velocity data in Fig. 3. As this equatorward expansion of the openclosed field line boundary continued, enhanced electron and ion temperatures were seen above the ESR, in response to the precipitation and convection flow. Between 06:35 and 07:01, the ESR was in the cusp/cleft region, as defined by the MSP. The general convection and precipitation features were as in Fig. $10 \mathrm{~b}$ and this interpretation is supported by the distribution of flow and backscatter observed by the CUTLASS Finland radar. The CUTLASS flow pattern, derived from the Finland radar data using a beam-swinging technique, is shown in Fig. 11. Although the area of coverage is not as large as in Fig. 10, it is clear that the main features of the schematic are reproduced in the data. Note from the schematic that flow streamlines cross non-reconnecting segments of the open/closed boundary, where such a boundary is moving equatorward (Siscoe and Huang, 1985). The ionospheric projection of the reconnection $X$ line is shifted towards dawn, as expected for this orientation of the IMF (Cowley et al., 1991). A detailed study of this intersection of the cusp/cleft is presented by Lockwood et al. (2000). The ion temperature rises were highly structured, showing that the strong eastward velocities (driven by the tension force on newly opened field lines) were pulsed. This is consistent with the predictions for pulsed magnetopause reconnection when the IMF $\left|B_{y}\right|$ is large (Lockwood et al., 1989a, b, 1995).

After 07:01 UT, the cusp/cleft had moved fully southward of the ESR site, which then measured the very low electron densities characteristic of the winter polar cap. Plasma velocities were eastward and faster than in the cusp/cleft (giving consistently high ion temperatures). This may in part have reflected the observed increasingly negative IMF $B_{y}$, but probably also reflected the spatial pattern of the convection, as shown in Fig. 10c.

After 07:30 UT, we observed the ionospheric response to a second sharp reversal in the direction of IMF $B_{z}$, this time from southward to northward. The auroral luminosity and the band of enhanced electron temperatures reversed its southward progress, until by 07:50 UT it had once again reached the latitude of the ESR. At this point, the densities measured by the ESR began to increase slowly, until they were a factor of ten greater than the lowest values and the return of elevated electron temperatures confirmed that soft particle precipitation was once more occurring above the radar. Enhanced ion temperatures were absent above the ESR during this contraction and the VHF radar data show that they decayed at all latitudes.

The bifurcation of the cusp/cleft aurora (discussed in Sect. 3.4) and the associated band of high electron temperatures (Sect. 3.1) justifies a more detailed 


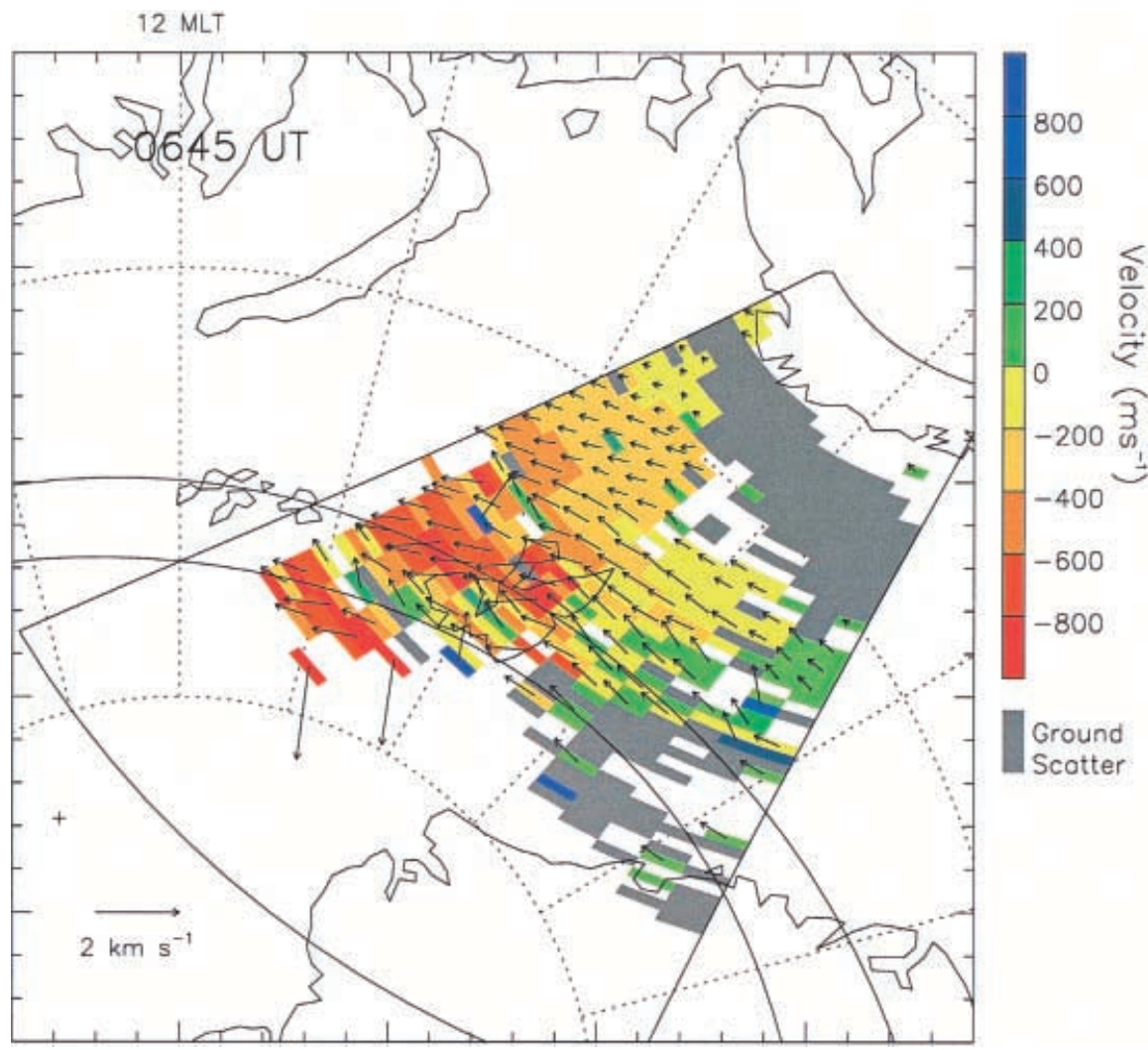

Fig. 11. Velocity field for 06:45 UT on December 16th 1998, as derived from the CUTLASS Finland radar data, using a beam-swinging technique. Colour contours are used to indicate the magnitude of the flow vectors. The derived velocities can be seen to reproduce the salient features of the schematic flow pattern for this interval, shown in Fig. 10b discussion. As shown in Fig. 3, the VHF radar detected weak sunward convection after 07:45, as opposed to strong anti-sunward convection before 07:25. Since $B_{z}$ turned northward during this interval, the implication is that lobe reconnection was taking place in the northern hemisphere, despite what Lockwood and Moen (1999) propose to be a disadvantageous IMF orientation. As observed and explained by Øieroset et al. (1997) and Lockwood and Moen (1999), this lobe reconnection initially maps to the poleward edge of the remnant cusp produced by low-latitude reconnection during the prior period of southward IMF. However, as lobe reconnection continues, the projection of the $\mathrm{X}$-line migrates poleward (away from the open-closed boundary), as "old" lobe field lines (opened in the prior period of southward IMF) are converted into "overdraped lobe" field lines (Crooker, 1992). What is interesting in the present data is that the equatorward edge of the cusp/ cleft aurora, which persisted at lower intensities, did not migrate poleward, indeed it seemed to erode equatorward. This behaviour can be seen in the VHF data (Fig. 2, panel 2) where two distinct regions of enhanced electron temperature, apparently moving in opposite directions, can be seen during the interval 08:08-08:30. The same structure is seen in the CUTLASS data which displays two distinct regions of enhanced spectral width (best seen in the middle panel of Fig. 7a, in a beam that points further west than the ESR, at times just before 08:00 UT). The MSP data also show two latitudinally separated regions of emission at around 08:15 UT, though the location of the equatorward band is close to the southern edge of the viewing area, making it difficult to infer its precise evolution. The apparent equatorward erosion is opposite to the behaviour in the northward turning observed by Lockwood and Moen (1999), in which the equatorward band migrated poleward, seemingly in response to enhanced reconnection in the opposite hemisphere which closed overdraped field lines.

This behaviour strongly supports the suggestion that subsolar reconnection, which generates new open flux, was also taking place at this time even though the IMF was northward and lobe reconnection was taking place. This has been proposed by a number of authors (Onsager and Fuselier, 1994; Fuselier et al., 1995; Chandler et al., 1999) from detailed consideration of the distribution functions of both ion (magnetosheath and ionospheric) and electron populations at the magnetopause during northward IMF conditions. Weiss et al. (1995) have invoked the simultaneous existence of both reconnection processes to explain a spatial distribution of cusp/cleft aurora and the pattern of ion dispersion observed by DE-1 during a flight through it, also under northward IMF conditions. Anderson et al. (1997) argue that draping of a weakly northward IMF in the plasma depletion layer just outside the magnetopause, makes the required reconnection geometry possible by generating the required magnetic shear across the magnetopause.

Before the equatorward part of the aurora eroded southward (at 08:00) the IMF components were $B_{z} \approx 7 \mathrm{nT}$ and $B_{y} \approx-2 \mathrm{nT}$, (giving an IMF clock angle $\theta$ of about $344^{\circ}$ ), whereas by $08: 15$ these had changed to $B_{z} \approx 1 \mathrm{nT}$ and $B_{y} \approx-2 \mathrm{nT},\left(\theta\right.$ of $\left.297^{\circ}\right)$. Sandholt et al. 
(1998a, b) have shown that the aurorae associated with both subsolar and lobe reconnection are present if the IMF clock angle is within $45^{\circ}$ of the magnetic equatorial plane $\left(\theta\right.$ of $45-90^{\circ}$ and $270-315^{\circ}$ ). Thus the change in IMF clock angle orientation that took place during the second period of northward IMF appears to have been sufficient to allow subsolar reconnection to commence as well as lobe reconnection to continue. The location of the ESR at 08:30, between the two resulting aurorae, is sketched schematically in Fig. 10d. There is some evidence for the re-appearance of a lobe convection cell in the lower panel of Fig. 3, where the strong eastward flows at high latitudes are seen to be replaced by weaker, disordered, mostly westward flows after the IMF $B_{z}$ turns northward.

The present observations are similar, but not identical to, those presented by Sandholt et al. (1998a). These authors also observed a bifurcation in the cusp aurora, which they attributed to simultaneous high- and lowlatitude reconnection. In their case, the low-latitude band of precipitation did not move southward, however, but remained at fixed magnetic latitude. The observations of Sandholt et al. (1989a) therefore could not prove conclusively that the low-latitude feature arose from subsolar reconnection, rather than being on closed field lines in the LLBL. In the observations reported here, the observed southward erosion of the low-latitude cusp aurora could only arise if this feature was on reconnecting field lines, strongly suggesting that lobe reconnection and subsolar reconnection must be occurring simultaneously.

\subsection{Field-aligned flows and the cleft ion fountain}

Figure 1 shows that strong field-aligned upflows were seen in the vicinity of the southward-IMF cusp/cleft. These commenced in response to the elevated ion temperatures (at 06:25), before the electron temperatures rose (at 06:36). Similarly they persisted into the polar cap (after 07:05) where ion, but not electron, temperatures were high. On the other hand, weaker field-aligned flows were later seen in the northwardIMF cusp/cleft (07:50-08:10), where electron, but not ion, temperatures were raised.

It therefore appears that enhancements in both electron and ion temperatures can drive upflows in the cusp/cleft region, but these are strongest if the ion temperature is raised. The east-west convection flows on newly opened field lines caused by the tension force appear to enhance the field-aligned upflows, which should thus be strongest when IMF $\left|B_{y}\right|$ is large. This will change the flux of source particles which are energised at greater altitudes to give the cleft ion fountain outflows (Lockwood et al., 1985a, b).

As the ESR moved deeper into the polar cap, the ion temperature enhancement decayed away with the tension force as the newly opened field lines straightened. Figure 1 shows that the field-aligned upflows turned to strong return downflows once this happened. Thus the response of field-aligned flow to the passage of the field line through the cusp region was as predicted by Whitteker (1977).

\section{Conclusions}

The ESR data showed clear signatures of the cusp/cleft aurora. However, these were very structured and complex and can, at present, only be interpreted with a great deal of supporting observations that give the latitudinal structure and motions. In particular, the MSP optical observations of the aurora and the VHF radar observations of enhanced electron temperatures have been vital in terms of telling us where the radar is in relation to the cusp/cleft precipitation as it moves in response to IMF changes.

Under northward IMF conditions, we find that the precipitation region bifurcated, in a way that strongly supports the concept that both subsolar and lobe reconnection took place simultaneously when the IMF vector was northward but relatively close to the magnetic equatorial plane. In this case, the northwardIMF cleft/LLBL was on newly opened field lines, as has been suggested for southward IMF.

Under southward IMF conditions the equatorward-expanding cusp/cleft was more highly structured than under northward IMF, when it was retreating poleward again. In particular, the southward IMF showed highly structured and strong ion heating consistent with rapid east/west motion of field lines opened by magnetopause reconnection. The structured nature of the ion heating was consistent with pulsed reconnection signatures.

Stronger upflows to feed the cleft ion fountain were driven when the IMF pointed southward and $\left|B_{y}\right|$ was large. These upflows appeared to be enhanced by the ion heating associated with the fast convection flows caused by the curvature ("tension") force on newly opened field lines. For the northward-IMF cusp/cleft, weaker upflows were still seen in response to the electron temperature enhancements. These were found in association with the cusp/cleft precipitation and aurora. Inside the polar cap, where neither the tension force nor the cusp/ cleft precipitation were present, the field-aligned flows turned to downward.

Acknowledgements. The authors are grateful to the director and staff of the EISCAT Scientific Association for providing the radar facilities and assistance with making the observations. EISCAT is an international association, supported by the research councils of Finland, France, Germany, Japan, Norway, Sweden and the United Kingdom. We are also grateful to Truls Hansen of the University of Oslo for providing the magnetometer data, and wish to thank the Department of Physics, University of Oslo for giving us access to their database of optical recordings from Ny Ålesund. The operation of the CUTLASS Finland radar is supported by PPARC, the Swedish Institute for Space Physics, Uppsala and the Finnish Meteorological Institute, Helsinki. The authors acknowledge R. Lepping at NASA/GSFC for the use of the spacecraft data. I.W.M. and M.L. are funded by the UK Particle Physics and Astronomy Research Council and J.M. by the Norwegian Research Council and UNIS grant 9/963. The Editor-in-chief thanks M. Rietveld for his help in evaluating this paper. 


\section{References}

Akasofu, S. I., E. W. Jr. Hones, S. J. Bame, J. R. Ashbridge, and A. T. Y. Lui, Magnetotail and boundary layer plasma at geocentric distance of $18 \mathrm{R}_{\mathrm{E}}, J$. Geophys. Res., 78, 7257-7263, 1973.

Anderson, B. J., T. D. Phan, and S. A. Fuselier, Relationships between plasma depletion and subsolar reconnection, J. Geophys. Res., 102, 9531-9542, 1997.

Baker K. B., J. R. Dudeney, R. A. Greenwald, M. Pinnock, P. T. Newell, A. S. Rodger, N. Mattin, and C.-I. Meng, HF radar signatures of the cusp and low-latitude boundary layer, J. Geophys. Res., 100, 7671-7695, 1995.

Burch, J. L., Rate of erosion of dayside magnetic flux based on a quantitative study of polar cusp latitude on the interplanetary magnetic field, Radio Sci., 8, 955-961, 1973.

Burke, W. J., M. C. Kelley, R. C. Sagalyn, M. Smiddy, and S. T. Lai, Polar cap electric field structures with northward interplanetary magnetic field, Geophys. Res. Lett., 6, 21-24, 1979.

Carbary, J. F., and C.-I. Meng, Correlation of cusp width with AE(12) and $B_{z}$, Planet. Space Sci., 36, 157-161, 1988.

Chandler, M. O., S. A. Fuselier, M. Lockwood, and T. E. Moore, Evidence of component magnetic merging equatorward of the cusp, J. Geophys. Res., 104, 22 623-22 648, 1999.

Cowley, S. W. H., J. P. Morelli, and M. Lockwood, Dependence of convective flows and particle precipitation in the high-latitude dayside ionosphere on the $\mathrm{X}$ and $\mathrm{Y}$ components of the interplanetary magnetic field, J. Geophys. Res., 96, 5557-5564, 1991.

Crooker, N. U., Reverse convection, J. Geophys. Res., 97, 19 363$19372,1992$.

Crooker, N. U., and F. J. Rich, Lobe-cell convection as a summer phenomenon, J. Geophys. Res., 98, 13 403-13 407, 1993.

Cumnock, J. A., R. A. Heelis, and M. R. Hairston, Response of the ionospheric convection pattern to a rotation of the interplanetary magnetic field on January 14 1988, J. Geophys. Res., 97, 19 449-19 460, 1992.

Curtis, S. A., W. R. Hoegy, L. H. Brace, N. C. Maynard, and M. Suguira, DE-2 Cusp observations: role of plasma instabilities in topside ionosphere heating and density fluctuations, Geophys. Res. Lett., 9, 997-1000, 1982.

Davies J. A., M. Lester, and I. W. McCrea, A statistical study of ion frictional heating observed by EISCAT, Ann. Geophys., 15, 1399-1411, 1997.

Davis, C. J., and M. Lockwood, Predicted signatures of pulsed reconnection in ESR data, Ann. Geophys., 14, 1246-1256, 1996.

Eastman, T. E., E. W. Jr. Hones, S. J. Bame, and J. R. Ashbridge, The magnetospheric boundary layer: site of plasma, momentum and energy transfer from the magnetosheath to the magnetosphere, Geophys. Res. Lett., 3, 685-688, 1976.

Etemadi, A., S. W. H. Cowley, and M. Lockwood, The effect of rapid changes in ionospheric flow on velocity vectors deduced from radar beam-swinging experiments, J. Atmos. Terr. Phys., 51, 125-138, 1989.

Fedorov, A., E. Budnik, M. Novrachev, V. Romanov, P. Song, and J.-A. Savaud, Plasma characteristics near the exterior cusp under different orientations of the interplanetary magnetic field, Czech J. Phys., 49, 711-732, 1999.

Fox, N. J., M. Lockwood, S. W. H. Cowley, M. P. Freeman, E. Friis-Christensen, D. K. Milling, M. Pinnock, and G. D. Reeves, EISCAT observations of unusual flows in the morning sector associated with weak substorm activity, Ann. Geophys., 12, 541-553, 1994.

Freeman, M. P., J. M. Ruohoniemi, and R. A. Greenwald, The determination of time-stationary two-dimensional convection patterns with single-station radar, J. Geophys. Res., 96, 15735 $15749,1991$.

Freeman, M. P., C. J. Farrugia, L. F. Burlaga, M. R. Hairston, M. E. Greenspan, J. M. Ruohoniemi, and R. P. Lepping, The interaction of a magnetic cloud with the Earth: ionospheric convection in the northern and southern hemispheres for a wide range of quasi-steady interplanetary magnetic field conditions, J. Geophys. Res., 98, 7633-7655, 1993.

Fuselier, S. A., B. J. Anderson, and T. G. Onsager, Electron and ion signatures of field line topology at the low shear magnetopause, J. Geophys. Res., 100, 11 805-11 814, 1995.

Fuselier, S. A., M. Lockwood, T. G. Onsager, and W. K. Peterson, The source population for the cusp and cleft/LLBL for southward IMF, Geophys. Res. Lett., 26, 1665-1669, 1999.

Haerendel, G., G. Paschmann, N. Sckopke, H. Rosenbauer, and P. C. Hedgecock, The frontside boundary layer of the magnetopause and the problem of reconnection, J. Geophys. Res., 83, 3195-3216, 1978.

Hall, D. S., C. P. Chanelor, D. A. Bryant, D. R. Lepine, and V. P. Tritakis, Electrons in the boundary layers near the dayside magnetopause, J. Geophys. Res., 96, 7869-7892, 1991.

Hones, E. W., Jr., J. R. Ashbridge, S. J. Bame, M. D. Montgomery, S. Singer, and S.-I. Akasofu, Measurements of magnetotail plasma flow made with Vela 4B, J. Geophys. Res., 77, 55035522, 1972.

Horwitz, J. L., and S.-I. Akasofu, The response of the dayside aurora to sharp northward and southward transitions of the interplanetary magnetic field and to magnetospheric substorms, J. Geophys. Res., 82, 2723-2734, 1977.

Knipp, D. J., B. A. Emery, A. D. Richmond, and N. U. Crooker, et al., Ionospheric convection response to strong, slow variations in a northward interplanetary magnetic field: a case study for January 14, 1988, J. Geophys. Res., 98, 19 273-19 292, 1993.

Lockwood, M., The location and characteristics of the reconnection $\mathrm{X}$-line deduced from low-altitude satellite and ground-based observations, 1, Theory, J. Geophys. Res., 100, 21 791-21 802, 1995.

Lockwood, M., and S. W. H. Cowley, Ionospheric convection and the substorm cycle, in Substorms 1, Proc. 1st. Int. Conf. Substorms, ICS-1, Ed. C. Mattock, European Space Agency Publications, Nordvijk, The Netherlands, ESA-SP-335, 99-109, 1992.

Lockwood, M., and M. A. Hapgood, How the magnetopause transition parameter works, Geophys. Res. Lett., 24, 373-376, 1997.

Lockwood, M., and M. A. Hapgood, On the cause of a magnetospheric flux transfer event, J. Geophys. Res., 103, $26453-$ 26 478, 1998.

Lockwood, M., and J. Moen, Ion populations on open field lines within the low-latitude boundary layer: theory and observations during a dayside transient event, Geophys. Res. Lett., 23, 28952898, 1996.

Lockwood, M., and J. Moen, Reconfiguration and closure of lobe flux by reconnection during northward IMF: evidence for signatures in cusp/cleft auroral emissions, Ann. Geophys., 17, 996-1011, 1999.

Lockwood, M., and M. F. Smith, Low- and mid-altitude cusp particle signatures for general magnetopause reconnection rate variations, I, Theory, J. Geophys. Res., 99, 8531-8555, 1994.

Lockwood, M., M. O. Chandler, J. L Horwitz, J. H. Jr. Waite, T. E. Moore, and C. R. Chappell, The cleft ion fountain, $J$. Geophys. Res., 90, 9736-9748, 1985a.

Lockwood, M., T. E. Moore, J. H. Waite, C. R. Chappell, J. L. Horwitz, and R. A. Heelis, The geomagnetic mass spectrometer - mass and energy dispersions of ionospheric ion flows into the magnetosphere, Nature, 316, 612-613, 1985b.

Lockwood, M., P. E. Sandholt, and S. W. H. Cowley, Dayside auroral activity and momentum transfer from the solar wind, Geophys. Res. Lett., 16, 33-36, 1989a.

Lockwood M., P. E. Sandholt, S. W. H. Cowley, and T. Oguti, Interplanetary magnetic field control of dayside auroral activity and the transfer of momentum across the dayside magnetopause, Planet. Space Sci., 37, 1347-1365, 1989b.

Lockwood, M., J. Moen, S. W. H. Cowley, A. D. Farmer, U. P. Løvhaug, H. Lühr, and V. N. Davda, Variability of dayside 
convection and motions of the cusp/cleft aurora, Geophys. Res. Lett., 20, 1011-1014, 1993.

Lockwood, M., S. W. H. Cowley, P. E. Sandholt, and U. P. Løvhaug, Causes of plasma flow bursts and dayside auroral transients: an evaluation of two models invoking reconnection pulses and changes in the Y-component of the magnetosheath field, J. Geophys. Res., 100, 7613-7626, 1995.

Lockwood, M., S. W. H. Cowley, and T. G. Onsager, Ion acceleration at both the interior and exterior Alfvén waves associated with the magnetopause reconnection site: signatures in cusp precipitation, J. Geophys. Res., 101, 21 501-21 515, 1996.

Lockwood, M., I. W. McCrea, S. E. Milan, J. Moen, J. C. Cerisier, and A. Thorolfsson, Plasma structure within poleward-moving cusp/cleft auroral transients: EISCAT Svalbard radar observations and an explanation in terms of large local time extent of events, Ann. Geophys., this issue, 2000.

Lotko, W., and B. U. O. Sonnerup, The low-latitude boundary layer on closed field lines, in Physics of the magnetopause, Eds. P. Song, B. U. Ö. Sonnerup, M. Thompsen, Geophys. Monogr., 90, 371-383, 1995.

Maezawa, K., Magnetosphere convection induced by the positive and negative $\mathrm{Z}$ components of the interplanetary magnetic field: quantitative analysis using polar cap magnetic records, J. Geophys. Res., 81, 2289-2303, 1976.

Maynard N. C., W. J. Burke, R. F. Pfaff, and E. Weber, et al., Driving dayside convection with northward IMF: observations by a sounding rocket launched from Svalbard, J. Geophys. Res., 105, 5245-5264, 2000 .

McCrea, I. W., and M. Lockwood, Incoherent scatter radars, in Ground-based observations in support of the Cluster mission, Eds. M. Lockwood, M. N. Wild, H. J. Opgenoorth ESA Publications, ESTEC, Nordvijk, The Netherlands, ESA-SP-1198, 239266, 1997.

McCrea, I. W., M. Lester, T. R. Robinson, N. M. Wade, and T. B. Jones, On the identification and occurrence of ion frictional heating events in the high-latitude ionosphere, J. Atmos. Terr. Phys., 53, 587-597, 1991.

McCrea, I. W., M. Lester, T. R. Robinson, J.-P. St.-Maurice, N. M. Wade, and T. B. Jones, Derivation of the ion temperature partition coefficient $\beta_{\text {para }}$ from the study of ion frictional heating events, J. Geophys. Res., 98, 15 701-15 715, 1993.

Milan S. E., T. K. Yeoman, M. Lester, E. C. Thomas, and T. B. Jones, Initial backscatter statistics from the CUTLASS HF radars, Ann. Geophys., 15, 703-718, 1997.

Moen, J., D. Evans, H. C. Carlson, and M. Lockwood, Dayside moving auroral transients related to LLBL dynamics, Geophys. Res. Lett., 23, 3247-3250, 1996.

Moen, J., D. A. Lorentzen, and F. Sigernes, Dayside moving auroral forms and bursty proton auroral events in relation to particle boundaries observed by NOAA-12, J. Geophys. Res., 103, 14 855-14 863, 1998.

Newell, P. T., and C.-I. Meng, Cusp width and $B_{z}$ : observations and a conceptual model, J. Geophys. Res., 92, 13 673-13 678, 1987.

Newell, P. T., and C.-I. Meng, The cusp and the cleft/LLBL: low altitude identification and statistical local time variation, J. Geophys. Res., 93, 14 549-14 556, 1988.

Newell, P .T., and C.-I. Meng, Mapping the dayside ionosphere to the magnetosphere according to particle precipitation characteristics, Geophys. Res. Lett., 19, 609-612, 1992.

Newell, P. T., and C.-I. Meng, Open and closed low-latitude boundary layer, in Polar cap boundary phenomena, Eds. J. Moen, A. Egeland, NATO ASI Ser C, Kluwer, Dordrecht, 509, 91-102, 1998.

Newell, P. T., C.-I. Meng, D. G. Sibeck, and R. Lepping, Some lowaltitude cusp dependencies on the interplanetary magnetic field, J. Geophys. Res., 94, 8921-8927, 1989.

Nishida, A., Can random reconnection on the magnetopause produce the low-latitude boundary layer?, Geophys. Res. Lett., 16, 227-230, 1989.
Ogilvie, K., R. J. Fitzenreiter, and J. D. Scudder, Observations of electron beams in the low-latitude boundary layer, J. Geophys. Res., 89, 10 723-10 732, 1984.

Øieroset, M., P. E. Sandholt, W. F. Denig, and S. W. H. Cowley, Northward interplanetary magnetic field cusp aurora and highlatitude magnetopause reconnection, J. Geophys. Res., 102, $11349-11362,1997$.

Onsager, T. G., and S. A. Fuselier, The location of the magnetopause reconnection for northward and southward interplanetary magnetic field, in Solar system plasmas in space and time, Geophys. Monogr. Ser., Eds. J. L. Burch, J. H. Jr. Waite Am. Gephys. Union, Washington, D. C., 84,. 183197, 1994

Onsager, T. G., and M. Lockwood, High-latitude particle precipitation and its relationship to magnetospheric source regions, Space Sci. Rev., 80, 77-107, 1997.

Onsager T. G., C. A. Kletzing, J. B. Austin, and H. MacKiernan, Model of magnetosheath plasma in the magnetosphere: cusp and mantle particles at low altitudes, Geophys. Res. Lett., 20, 479-482, 1993.

Richard, R. L., R. J. Walker, and M. Ashour-Abdalla, The population of the magnetosphere by solar wind ions when the interplanetary magnetic field is northward, Geophys. Res. Lett., 21, 2455-2458, 1994.

Rosenbauer, H., H. Gruenwaldt, M. D. Montgomery, G. Paschmann, and N. Skopke, HEOS-2 plasma observations in the distant polar magnetosphere: the plasma mantle, J. Geophys. Res., 80, 2723-2737, 1975.

Sandholt, P. E., Auroral electrodynamics at the cusp/cleft poleward boundary during northward interplanetary magnetic field, Geophys. Res. Lett., 18, 805-808, 1991.

Sandholt, P. E., M. Lockwood, W. F. Denig, R. C. Elphic, and S. Leontjev, Dynamical auroral structure in the vicinity of the polar cusp: multipoint observations during southward and northward IMF, Ann. Geophys., 10, 483-497, 1992.

Sandholt, P. E., C. J. Farrugia, M. Øieroset, P. Stauning, and S. W. H. Cowley, Auroral signature of lobe reconnection, Geophys. Res. Lett., 23, 1725-1728, 1996.

Sandholt, P. E., C. J. Farrugia, J. Moen, S. W. H. Cowley, and B. Lybekk, Dynamics of the aurora and associated convection currents during a cusp bifurcation event, Geophys. Res. Lett., 25, 4313-4316, 1998a.

Sandholt, P. E., C. J. Farrugia, J. Moen, and B. Lybekk, The dayside aurora and its regulation by the interplanetary magnetic field, in Polar cap boundary phenomena, Eds. J. Moen, A. Egeland, M. Lockwood, NATO ASI Ser. C, Kluwer, Dordrecht, 509, 189-208, 1998b.

Sandholt, P. E., C. J. Farrugia, J. Moen, and S. W. H. Cowley, Dayside auroral configurations: responses to southward and northward rotations of the interplanetary magnetic field, J. Geophys. Res., in press, 2000.

Sedgemore-Schulthess, K. J. F., M. Lockwood, T. S. Trondsen, B. S. Lanchester, M. H. Rees, D. Lorentzen, and J. Moen, Coherent EISCAT Svalbard radar spectra from the dayside cusp/cleft and their implications for transient field-aligned currents, J. Geophys. Res., 104, 24 613-24 624, 1999.

Sigernes, F., J. Moen, D. A. Lorentzen, C. S. Deehr, R. W. Smith, M. Øieroset, B. Lybekk, and J. A. Holtet, SCIFER height measurements of the midmorning aurora, Geophys. Res. Lett., 23, 1889-1892, 1996.

Siscoe, G. L., and T. S. Huang, Polar cap inflation and deflation, J. Geophys. Res., 90, 543-547, 1985.

Song, P., and C. T. Russell, Model of the formation of the lowlatitude boundary layer for strongly northward interplanetary magnetic field, J. Geophys. Res., 97, 1411-1420, 1992.

Thorolfsson A., J. C. Cerisier, M. Lockwood, P. E. Sandholt, C. Senior, and M. Lester, Simultaneous optical and radar signatures of poleward-moving auroral forms, Ann. Geophys., this volume, 2000.

Treumann, R. A., J. LaBelle, and T. M. Bauer, Diffusion processes: an observational perspective, in Physics of the magnetopause, 
Eds. P. Song, B. U. Ö. Sonnerup, M. Thompsen, Geophys. Monogr., 90, 331-341, 1995.

Vorobjev, V. G., G. A. Gustafsson, G. V. Starkov, Y. I. Feldstein, and N. F. Shenina, Dynamics of day and night aurorae during substorms, Planet Space Sci., 23, 269-278, 1975.

Watermann, J., O. de la Beaujardiere, and P. T. Newell, Incoherent scatter radar observations of ionospheric signatures of cusp-like electron precipitation, J. Geomag. Geoelect., 44, 1195-1206, 1992.

Watermann, J., D. Lummerzheim, O. de la Beaujardiere, P. T. Newell, and F. J. Rich, Ionospheric footprint of magnetosheath like particle precipitation observed by an incoherent scatter radar, J. Geophys. Res., 99, 3855-3867, 1994.

Weiss, L. A., P. H. Reiff, E. J. Weber, H. C. Carlson, M. Lockwood, and W. K. Peterson, Flow-aligned jets in the magnetospheric cusp: results from the Geospace Environment
Modelling pilot programme, J. Geophys. Res., 100, 7649-7660, 1995.

Whitteker, J. H., The transient response of the topside ionosphere to precipitation, Planet. Space Sci., 25, 773-786, 1977.

Winser, K. J., M. Lockwood, and G. O. L. Jones, Non-thermal plasma observations using EISCAT: aspect angle dependence, Geophys. Res. Lett., 14, 957-960, 1987.

Winske, D., V. A. Thomas, and N. Omidi, Diffusion at the magnetopause: a theoretical perspective, in Physics of the magnetopause, Eds. P. Song, B. U. Ö. Sonnerup, M. Thompsen, Geophys. Monogr., 90, 321-330, 1995.

Zanetti, L. J., T. A. Potemra, T. Iijima, W. Baumjohann, and P. F. Bythrow, Ionospheric and Birkeland current distributions for northward interplanetary magnetic field: inferred polar cap convection, J. Geophys. Res., 89, 7453-7458, 1984. 